NIST Special Publication 1152

\title{
Latent Interoperability Transmission Specification
}

Will Chapman

Austin Hicklin

George Kiebuzinski

Peter Komarinski

John Mayer-Splain

Melissa Taylor

Rachel Wallner

http://dx.doi.org/10.6028/NIST.SP.1152

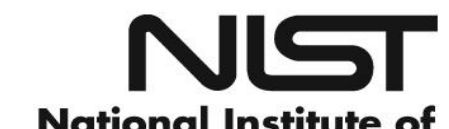

National Institute of Standards and Technology U.S. Department of Commerce 
NIST Special Publication 1152

\title{
Latent Interoperability Transmission Specification
}

\author{
Melissa Taylor \\ Law Enforcement Standards Office \\ Office of Special Programs
}

Will Chapman

Austin Hicklin

George Kiebuzinski

John Mayer-Splain

Rachel Wallner

Noblis

Falls Church, VA

Peter Komarinski

Komarinski \& Associates, LLC

Rotterdam, $N Y$

http://dx.doi.org/10.6028/NIST.SP.1152

January 2013

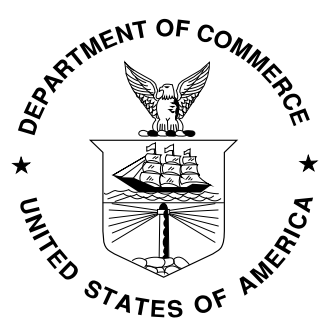

U.S. Department of Commerce Rebecca Blank, Acting Secretary

National Institute of Standards and Technology Patrick D. Gallagher, Under Secretary of Commerce for Standards and Technology and Director 
Certain commercial entities, equipment, or materials may be identified in this document in order to describe an experimental procedure or concept adequately. Such identification is not intended to imply recommendation or endorsement by the National Institute of Standards and Technology, nor is it intended to imply that the entities, materials, or equipment are necessarily the best available for the purpose.

National Institute of Standards and Technology Special Publication 1152

Natl. Inst. Stand. Technol. Spec. Publ. 1152, 46 pages (January 2013) http://dx.doi.org/10.6028/NIST.SP.1152

CODEN: NSPUE2 


\section{Latent Interoperability Transmission Specification}

January 2013

\footnotetext{
Abstract

The Latent Interoperability Transmission Specification (LITS) is an application profile of the American National Standard for Information Systems: Data Format for the Interchange of Fingerprint, Facial \& Other Biometric Information, American National Standards Institute/National Institute of Standards and Technology, Information Technology Laboratory (ANSI/NIST-ITL) 1-2011. LITS is a system-level specification, parallel to and compatible with the Federal Bureau of Investigation Criminal Justice Information Services Electronic Biometric Transmission Specification that focuses on the definition of vendor-neutral latent transactions to be exchanged among disparate cross-jurisdictional automated friction ridge identification systems (AFIS).

The purpose of LITS is to enable seamless, efficient hierarchical (from local to State to regional to Federal) and peer to peer (local to local, State to State, etc.) searches; to simplify acquisitions by defining a uniform latent AFIS data exchange format; and to enable the interchange of latent print annotation among examiners as part of non-AFIS casework.

LITS addresses latent AFIS interoperability between and among the States, local law enforcement agencies, regional organizations, and Federal organizations, such as the Department of Defense or the Department of Homeland Security.
} 


\section{Contents}

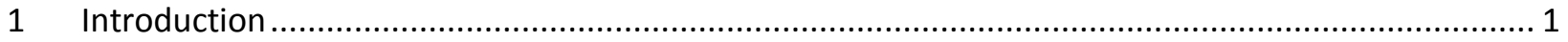

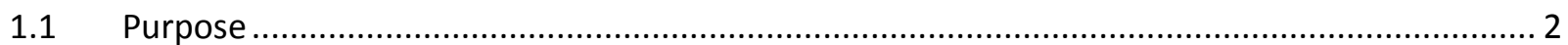

$1.2 \quad$ Scope

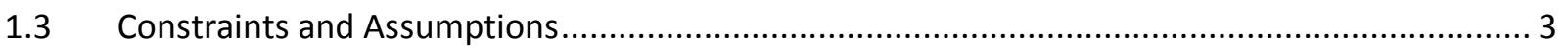

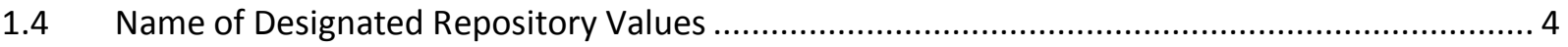

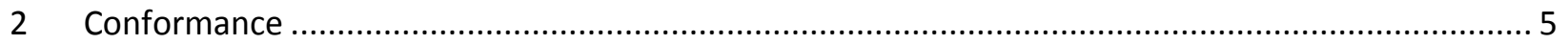

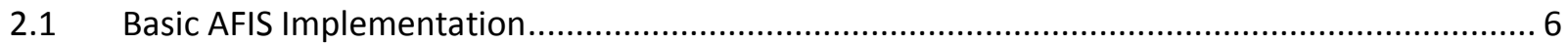

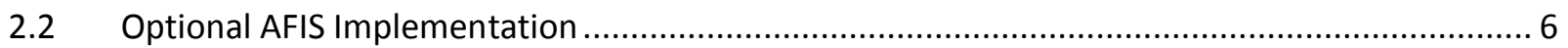

2.3 Casework Annotation and Exchange Implementation ........................................................ 7

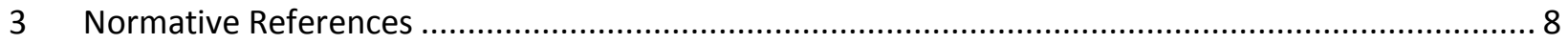

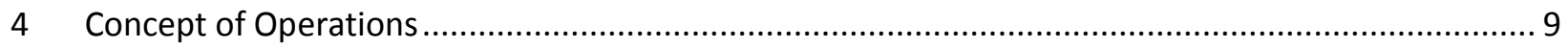

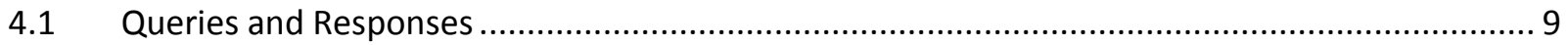

4.1.1 Latent Friction Ridge Searches and Responses......................................................... 9

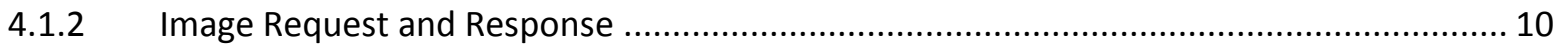

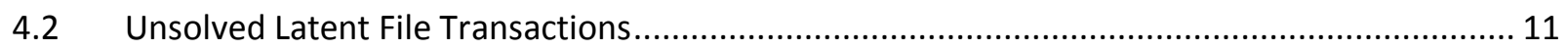

4.2.1 Unsolved Latent Match and Biometric Decision .......................................................... 11

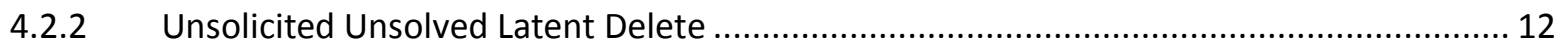

4.2.3 Unsolved Latent File Maintenance Transactions ...................................................... 12

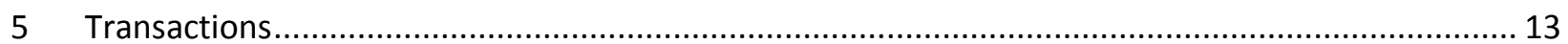

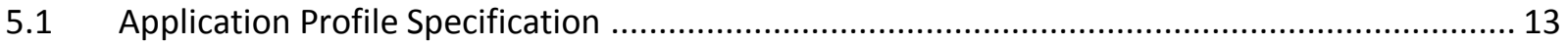

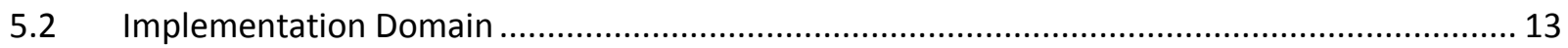

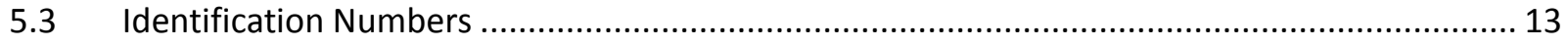

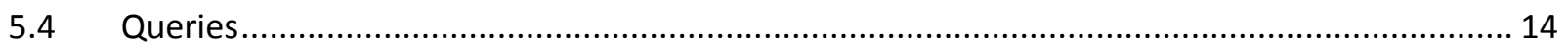

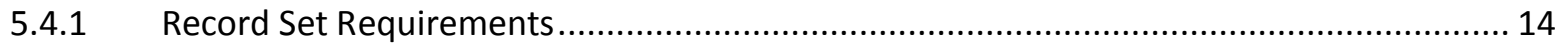

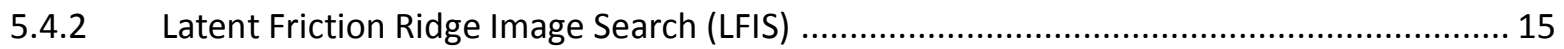

5.4.3 Latent Friction Ridge Features Search (LFFS) ......................................................... 15

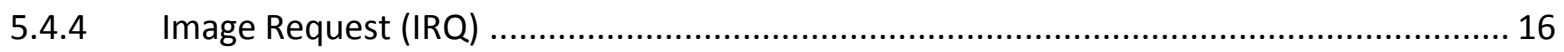

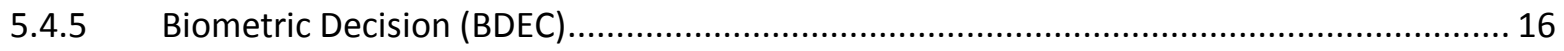

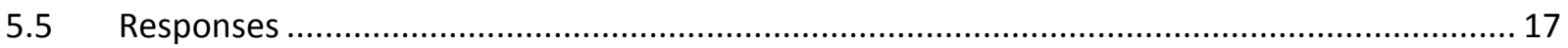

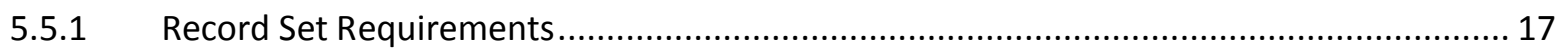

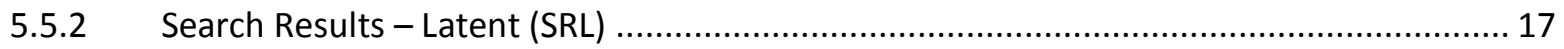

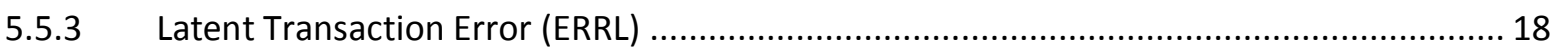

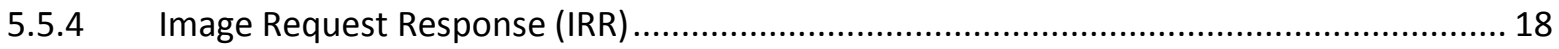

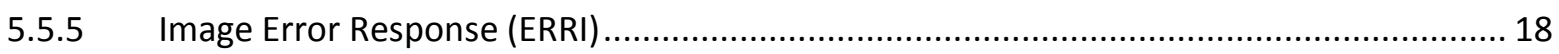

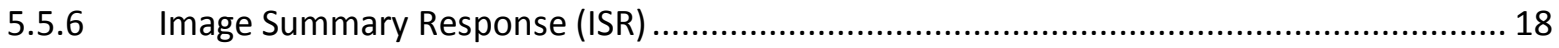

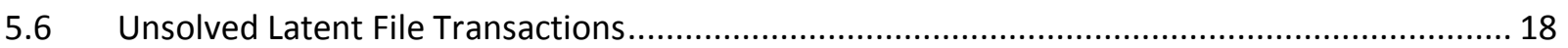

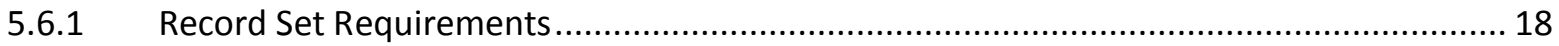

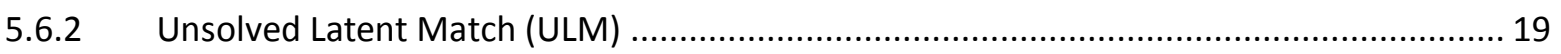

January 2013 
5.6.3 Unsolicited Unsolved Latent Delete (UULD) …......................................................... 19

5.6.4 Unsolved Latent Record Delete Request (ULD) ........................................................... 19

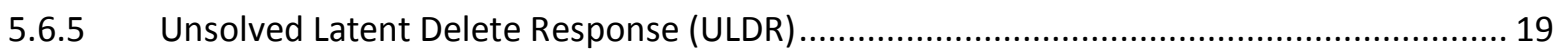

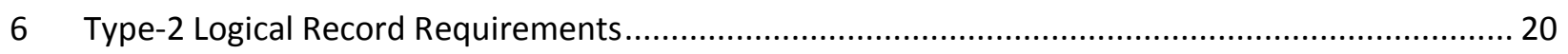

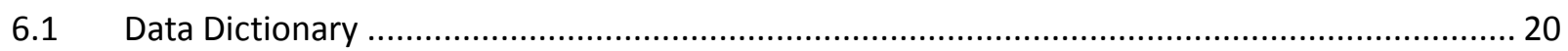

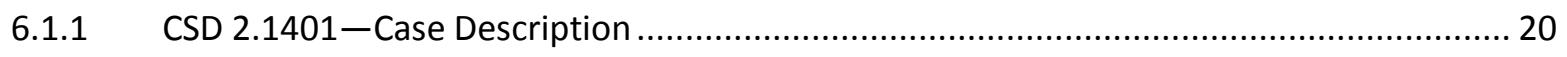

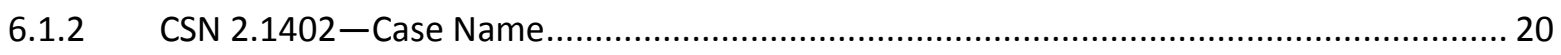

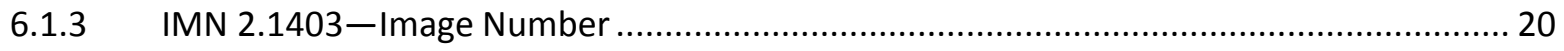

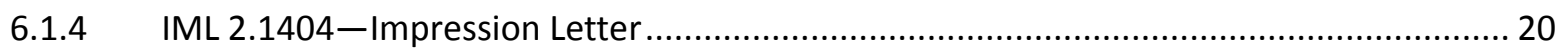

6.1.5 STR 2.1406-Source Transaction Reference ................................................................. 20

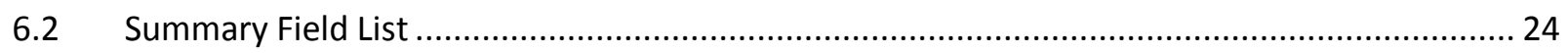

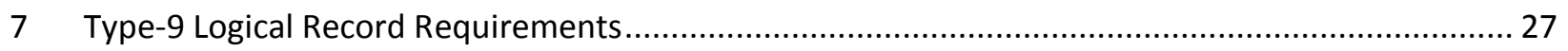

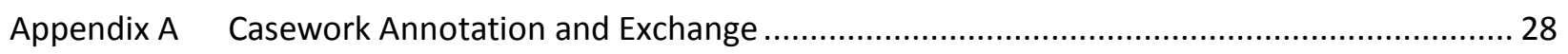

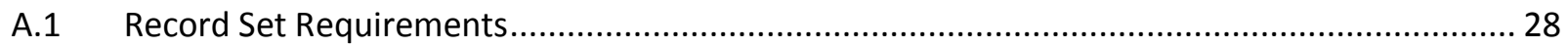

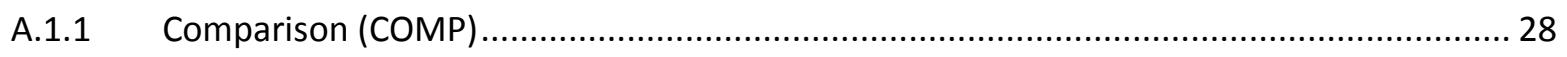

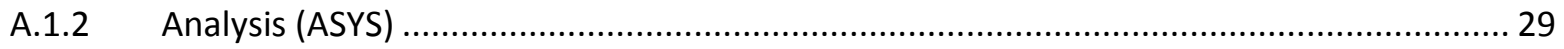

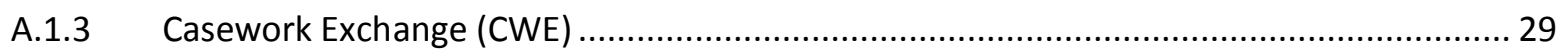

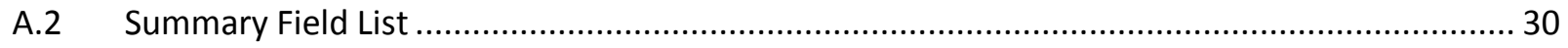

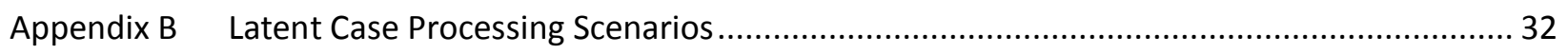

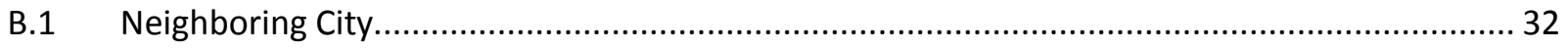

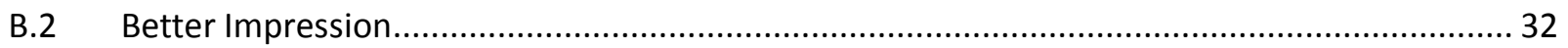

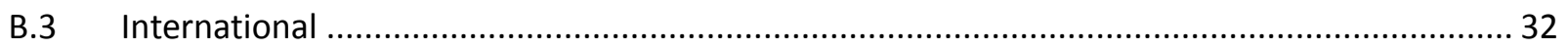

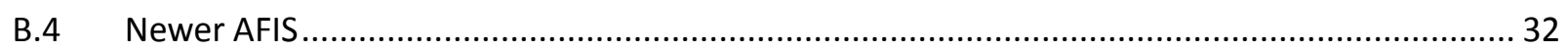

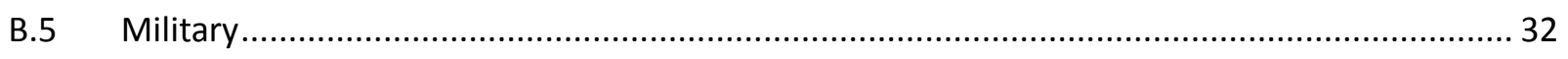

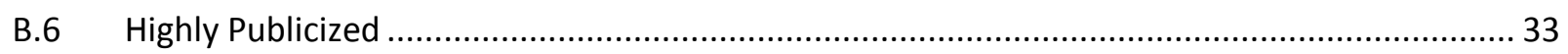

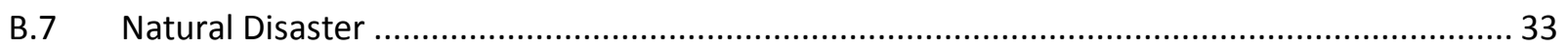

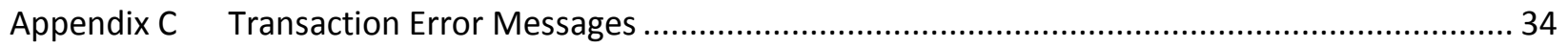

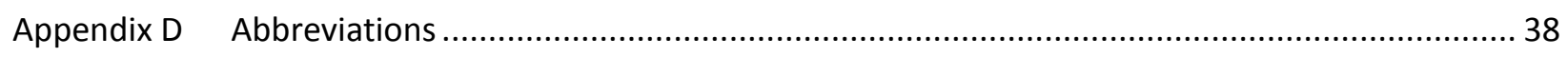




\section{Figures}

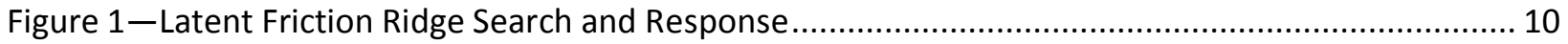

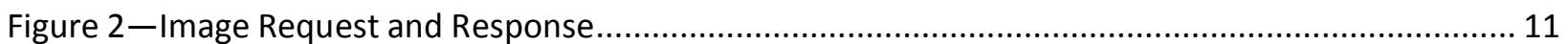

\section{Tables}

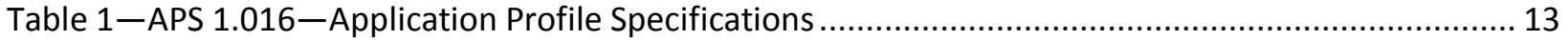

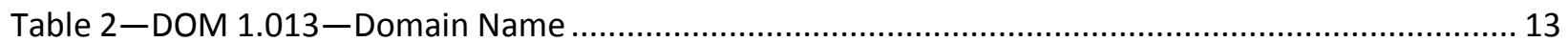

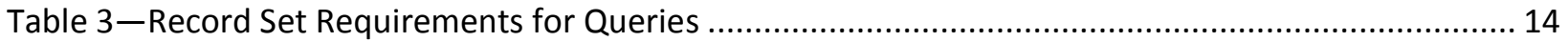

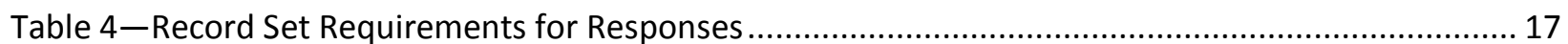

Table 5-Record Set Requirements for Unsolved Latent File Transactions .......................................... 18

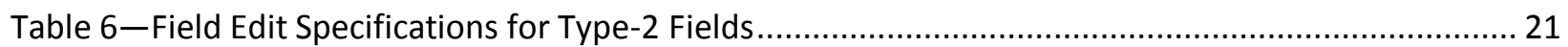

Table 7-STR 2.1406-Source Transaction Reference Information Items .............................................. 22

Table 8-Example of COMP Transaction Based on ANSI/NIST-ITL Transactions.................................... 23

Table 9-Example of COMP Transaction Based on Image Files. ............................................................ 23

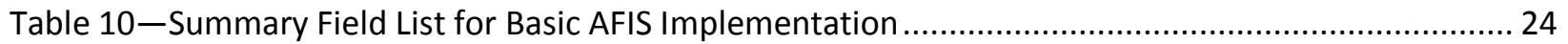

Table 11-Summary Field List for Optional AFIS Implementation ........................................................... 25

Table 12-Record Set Requirements for Casework Annotation and Exchange .................................... 28

Table 13-Summary Field List for Casework Annotation and Exchange .............................................. 30 


\section{Introduction}

The Latent Interoperability Transmission Specification (LITS) is in recognition of and response to the following factors:

- Recommendation $12^{1}$ in Strengthening Forensic Science in the United States: A Path Forward, ${ }^{2}$ a report by The National Academies of Science that identifies the need "to launch a new broadbased effort to achieve nationwide fingerprint data interoperability."

- The following limitations in the ability to search a latent print against another State or local database and the inability to communicate among disparate Automated Friction ridge Identification Systems (AFIS) need to be addressed

o There is no commonly accepted vendor-agnostic latent data exchange specification for use at the State/local level.

- There are differing rules for feature notation and extraction for each vendor.

- There is growing recognition of the need for latent print interoperability, as evidenced by the testimonies and data collected by the Executive Office of the President of the United States AFIS Interoperability Task Force and the National Institute of Standards and Technology (NIST)/National Institute for Justice AFIS Interoperability Working Group.

- The development of the Extended Feature Set (EFS) for friction ridge images provides a vendorneutral feature set that may be used to search the Federal Bureau of Investigation's (FBI's) Next Generation Identification (NGI) and databases of State and local agencies with different AFIS vendors. Testing of the EFS has shown that major AFIS system vendors can interoperate effectively using a common method of latent encoding. The EFS has been incorporated in American National Standard for Information Systems; Data Format for the Interchange of Fingerprint, Facial \& Other Biometric Information, American National Standards Institute/National Institute of Standards and Technology, Information Technology Laboratory 12011 (ANSI/NIST-ITL, 2011). ${ }^{3}$

- The development of EFS definitions enables the interchange of latent print annotation among examiners as part of non-AFIS casework.

${ }^{1}$ Recommendation 12 calls for the development of new standards. These include the following:

(a) standards for representing and communicating image and minutiae data among Automated Fingerprint Identification Systems. Common data standards would facilitate the sharing of fingerprint data among law enforcement agencies at the local, state, federal, and even international levels, which could result in more solved crimes, fewer wrongful identifications, and greater efficiency with respect to fingerprint searches; and

(b) baseline standards - to be used with computer algorithms - to map, record, and recognize features in fingerprint images, and a research agenda for the continued improvement, refinement, and characterization of the accuracy of these algorithms (including quantification of error rates).

${ }^{2}$ National Academy of Sciences. 2009. Strengthening Forensic Science in the United States: A Path Forward. http://www.nap.edu/catalog.php?record_id=12589.

${ }^{3}$ ANSI/NIST-ITL 1-2011 (NIST SP 500-290). Data Format for the Interchange of Fingerprint, Facial \& Other Biometric Information. http://www.nist.gov/itl/iad/ig/ansi standard.cfm. 
This specification is one of three interrelated specifications that have been designed to enable vendorneutral latent AFIS interoperability.

- Extended Feature Set Profile Specification (EFS Profiles) ${ }^{4}$-defines the sets of features to be used in latent friction ridge (fingerprint/palmprint or plantar ${ }^{5}$ ) AFIS searches. EFS Profiles is a supporting document to ANSI/NIST-ITL (2011).

(Note: EFS Profiles for fundamental latent AFIS transactions include the image.)

- Markup Instructions for Extended Friction Ridge Features (Markup) ${ }^{6}$-specifies a common set of instructions and data annotation guidelines for the markup of EFS features by latent print examiners.

- Latent Interoperability Transmission Specification (LITS)-completes the progression by providing definitions of transactions between exchanging agencies, which are expected to include, but not necessarily be limited to, State and local law enforcement agencies. LITS is a system-level specification, parallel to and compatible with the FBI Criminal Justice Information Services (CJIS) Electronic Biometric Transmission Specification (EBTS), that focuses on the definition of vendor-neutral latent transactions to be exchanged among disparate crossjurisdictional AFIS.

In this specification, the term "to mark" refers to the recording of latent friction ridge features (generally by a latent print examiner), and "markup" refers to the features so marked. ANSI/NIST-ITL (2011) defines the term "mark" as "the point where a needle has pierced the skin, usually associated with drug use," and in its introduction states, "The term 'marks' in some nations denotes what is called 'latent prints."'

\subsection{Purpose}

The purpose of LITS is to

- enable seamless, efficient hierarchical (local to State to regional to Federal) and peer to peer (local to local, State to State, etc.) searches

- simplify acquisitions by defining a uniform latent AFIS data exchange format

- enable the interchange of latent print annotation among examiners as part of non-AFIS casework

\footnotetext{
${ }^{4}$ Extended Feature Set Profile Specification. 2012. http://www.nist.gov/itl/iad/ig/ansi standard.cfm.

${ }^{5}$ Although friction ridge features defined for fingers also may be applicable to toes, they are explicitly excluded from the scope of this document because many of these characteristics, such as pattern classification, are undefined for toes as of this writing.

${ }^{6}$ Markup Instructions for Extended Friction Ridge Features. 2013. http://www.nist.gov/itl/iad/ig/ansi standard.cfm.
} 


\subsection{Scope}

LITS includes the following:

- a description of how to conform to this specification

- normative references for the implementation of this specification

- a description of the concept of operations for latent print interoperability

- definitions of the transactions and Type-2 Logical Record Requirements

LITS addresses latent AFIS interoperability between and among the States, local law enforcement agencies, regional organizations, and Federal organizations, such as the Department of Defense or the Department of Homeland Security.

\subsection{Constraints and Assumptions}

This specification is designed to facilitate interoperability between LITS-conformant AFIS systems. New systems may have LITS conformance at the time they are released, whereas legacy systems will have to plan for upgrade or migration.

LITS is specifically designed to be compatible with the FBI Integrated Automated Fingerprint Identification System (IAFIS) and NGI. By definition, a LITS-conformant system is compatible with FBI CJIS EBTS. With the exception of the Type-2 Logical Record Requirements (see section 6) and Casework Annotation and Exchange transaction (see appendix a), the fields and transactions in LITS are derived from the FBI CJIS EBTS.

Furthermore, it must be recognized that some interoperability may already exist and must be preserved when one of the exchanging parties adopts LITS.

LITS is predicated on the following:

- $\quad$ LITS is an application profile specification, built upon ANSI/NIST-ITL (2011).

- LITS is designed to be complementary to and compatible with the FBI CJIS EBTS.

- Interoperability must also define policy and legal aspects, generally specified in negotiated Memoranda of Understanding (MOU), as well as specification of connectivity, messaging, search volumes, and technical aspects, generally specified in negotiated Interface Control Documents (ICDs) and/or additional Service Level Agreements (SLAs). ${ }^{7}$

- These negotiated MOUs/ICDs should specify certain options that are supported by LITS:

o whether palms, fingertips, or lower joints may be exchanged using LITS transactions

- which EFS Profiles are required

- whether optional LITS transactions, such as Unsolved Latent File Transactions, are permitted and whether an exchanging agency permits additions to its Unsolved Latent File

\footnotetext{
${ }^{7}$ The content of MOUs, ICDs, and SLAs between exchanging agencies may vary and overlap.
} 
- whether candidate lists will be anonymized, such as by disallowing names in the Search Results-Latent (SRL) transaction or if receiving software or systems will be configured to hide candidate names

- LITS transactions are expected to be Law Enforcement Sensitive or contain Personally Identifiable Information and therefore must be secure in transmission. LITS assumes the negotiated ICD specifies security requirements and transport mechanisms. ${ }^{8}$

- Requests for Proposals for latent AFIS acquisitions may cite conformance with the LITS as a requirement.

- LITS assumes allocation of server-side computer resource time only and places no additional burden on server-side latent examiners' resources or time.

- $\quad$ LITS assumes the negotiated ICD may specify additional Type-2 fields to be exchanged, beyond those defined in LITS or FBI CJIS EBTS.

\subsection{Name of Designated Repository Values}

To conduct LITS transactions, AFIS owners must request a Name of Designated Repository (NDR) value by contacting interop@noblis.org. Assigned values of NDR for State and local systems are posted at http://www.noblis.org/interop.

According to FBI CJIS EBTS appendix C, the values 200-399 are reserved for State and local systems.

\footnotetext{
${ }^{8}$ The FBI requires that security for all systems connecting to the NGI be implemented in accordance with CJIS Security Policy Version 5.0, CJISD-ITS-DOC-08140-5.0, February 9, 2011.
} 


\section{Conformance}

The following terms are used in this specification to indicate mandatory requirements, recommended options, or permissible actions:

- The terms "shall" and "shall not" indicate requirements strictly to be followed to conform to this specification and from which no deviation is permitted.

- The terms "should" and "should not" indicate a recommended or particularly suitable choice when presented with several possibilities, without mentioning or excluding others, or when a certain course of action is preferred but not necessarily required, or when (in the negative form) a certain possibility or course of action is deprecated but not prohibited.

- The terms "may" and "need not" indicate a course of action permissible within the limits of this specification.

Conformance to this specification falls into the following classes:

- Basic AFIS Implementation

- Optional AFIS Implementation

- Casework Annotation and Exchange

To claim conformance to this specification, implementations shall provide the transactions for their conformance class, as defined below, in accordance with the transactions defined in Section 5Transactions; the requirements of Section 6-Type-2 Logical Record Requirements; and the requirements in Appendix A-Casework Annotation and Exchange.

A conformant AFIS shall accept Latent Friction Ridge Image Search (LFIS) and Latent Friction Ridge Features Search (LFFS) transactions as latent searches and Biometric Decision (BDEC) transactions as decision notifications. A conformant AFIS shall return Search Result-Latent (SRL) transactions as responses to LFFS or LFIS searches. All these transactions shall conform to the LITS, January 2013 (or later). LFIS transactions shall conform to EFS Profile 0: Image-Only Profile and LFFS transactions shall conform to, at a minimum, the EFS Profile 2: Quick Minutiae Search Profile as defined in EFS Profiles (or later); other profiles may be implemented optionally. These capabilities shall be demonstrated at delivery. These transactions shall be implemented for latent fingerprints; implementation for palmprints, extreme fingertips, or lower joints of the fingers is optional.

Conformant latent print workstation software shall be capable of the following:

- importing LFFS transactions conformant with LITS without loss of defined features

- $\quad$ exporting LFFS transactions conformant with LITS without loss of defined features

Such import and export functions shall be incorporated into the software and not rely on use of the FBI's Universal Latent Workstation software for translation. LITS is a peer of FBI CJIS EBTS, and therefore the exported LFFS transactions should be capable of being directly searched against the FBI's NGI system. 


\subsection{Basic AFIS Implementation}

A Basic AFIS Implementation shall provide the following transactions: ${ }^{9}$

- Latent Friction Ridge Image Search (LFIS)

- EFS Profile 0: Image-Only Profile

- Latent Friction Ridge Features Search (LFFS) ${ }^{10}$

- EFS Profile 2: Quick Minutiae Search Profile

- Image Request (IRQ)

- Biometric Decision (BDEC)

- Search Results - Latent (SRL)

- Latent Transaction Error (ERRL)

- Image Request Response (IRR)

- Image Error Response (ERRI)

\subsection{Optional AFIS Implementation}

An Optional AFIS Implementation may provide any or all of the following transactions in addition to the Basic AFIS Implementation:

- $\quad$ Latent Friction Ridge Features Search (LFFS) ${ }^{10}$

- EFS Profile 1: Minimal Markup Profile

- EFS Profile 3: Detailed Markup Profile

- EFS Profile 10: Skeleton Profile

- EFS Profile 11: Minutiae Ridge Count Profile

- EFS Profile 20: Legacy IAFIS Latent Feature Search Profile

- EFS Profile 21: Quick Minutiae Search Profile without Image

- EFS Profile 30: Search Response Profile with All, and Corresponding, Minutiae

- EFS Profile 31: Search Response Profile without Corresponding Minutiae

- EFS Profile 90: Full Annotation Profile

- $\quad$ Search Results - Latent (SRL)

- EFS Profile 30: Search Response Profile With All, and Corresponding, Minutiae

- EFS Profile 31: Search Response Profile Without Corresponding Minutiae

- Image Summary Response (ISR)

- Unsolved Latent Match (ULM)

- Unsolved Latent File Administrative Transactions

○ Unsolicited Unsolved Latent Delete (UULD)

- Unsolved Latent Record Delete Request (ULD)

○ Unsolved Latent Delete Response (ULDR)

\footnotetext{
${ }^{9}$ EFS Profiles 1-3 include the friction ridge image with the features. Per ANSI/NIST-ITL 7.7.9.1 Use of compression algorithms for friction ridge images, "Latent images shall not be compressed with any lossy compression algorithm. It is required that images be stored uncompressed, or that PNG [Portable Network Graphics] or other totally lossless compression algorithm be used for latent images."

${ }^{10}$ See EFS Profile Specification for EFS Profiles for maximized accuracy and Special-purpose and legacy profiles.
} 


\subsection{Casework Annotation and Exchange Implementation}

A Casework Annotation and Exchange Implementation may provide any or all of the following LITS transactions:

- Comparison (COMP)

- Analysis (ASYS)

- Casework Exchange (CWE)

These transactions are intended for exchange between human examiners or for archiving information associated with the Analysis, Comparison, Evaluation and Verification (ACE-V) process. These transactions are not intended for AFIS interaction.

The requirements for casework annotation and exchange are documented in appendix a. 


\section{Normative References}

The following referenced documents are indispensable for the application of this specification. For dated references, only the edition cited applies. For undated references, the latest edition of the referenced document (including any amendments) applies. All standards are subject to revision, and parties using this specification are encouraged to investigate the possibility of applying the most recent versions of the standards and documents indicated below.

ANSI/NIST-ITL (American National Standards Institute/National Institute of Standards and Technology, Information Technology Laboratory). 2011. American National Standards Institute/National Institute of Standards and Technology, Information Technology Laboratory: Data Format for the Interchange of Fingerprint, Facial \& Other Biometric Information, 1-2011, NIST Special Publication 500-290. http://biometrics.nist.gov/cs links/standard/AN ANSI 12011 standard.pdf.

FBI CJIS (Federal Bureau of Investigation Criminal Justice Information Services Electronic). 2011. Electronic Biometric Transmission Specification, IAFIS-DOC-01078-9.3. https://www.fbibiospecs.org/docs/EBTS v9 3 Final\%2012 $07 \quad 11$ clean.pdf.

NIST-OLES (National Institute of Standards and Technology, Law Enforcement Standards Office). Forthcoming. Extended Feature Set Profile Specification. http://www.nist.gov/itl/iad/ig/ansi standard.cfm.

NIST-OLES (National Institute of Standards and Technology, Law Enforcement Standards Office). Forthcoming. Markup Instructions for Extended Friction Ridge Features. http://www.nist.gov/itl/iad/ig/ansi_standard.cfm. 


\section{Concept of Operations}

LITS enables seamless, efficient hierarchical (local to State to regional to Federal) and peer to peer (local to local, State to State, etc.) searches between a latent examiner's own AFIS and any AFIS to which the latent examiner has access as permitted by an MOU. Currently, hierarchical searches are often based on nonstandard derivations of FBI CJIS EBTS, and the processes are often examiner-intensive and inefficient, especially for three-level hierarchies (AFIS systems at local, State, and IAFIS/NGI). Appendix B documents specific scenarios and use cases.

Latent case processing would be as follows:

- At the conclusion of normal latent print searches of the local/state AFIS, the examiner determines if the case is of sufficient importance to merit additional searches. ${ }^{11}$ If so, the case would be sent for external search, with options as to which external AFIS to search, such as IAFIS/NGI, another city partnered through an MOU, or another State partnered through an MOU.

- With the image already acquired and the features marked for the search on the examiners' own system, the features are exported and new features do not have to be marked (except to take advantage of optional EFS Profiles).

- A candidate list is returned for each of the external AFIS systems searched, and the examiner conducts comparisons with the candidates as usual. An image request may be conducted to obtain additional prints for specific subjects. If there is a match, the examiner notifies the requesting authorities who are handling the criminal case. The examiner would also remove the case from any Unsolved Latent File (ULF) on which it resides.

- If no match is found, the examiner decides whether to enroll the case on the ULF of the other AFIS if permitted by MOU, save the case for a later periodic Latent Print to Tenprint (LT/TP) search, remove the case entirely, etc.

\subsection{Queries and Responses}

\subsubsection{Latent Friction Ridge Searches and Responses}

Figure 1 depicts the transactions that provide interoperability between disparate, cross-jurisdictional AFIS systems. For the purposes of this workflow, Latent Friction Ridge Search is inclusive of both LFIS and LFFS. When latent examiners have exhausted all reasonable searches on their AFIS, they then have the opportunity to send that same search without any additional encoding effort to an AFIS in another jurisdiction.

\footnotetext{
${ }^{11}$ Policy may require serial searches or permit parallel searches.
} 


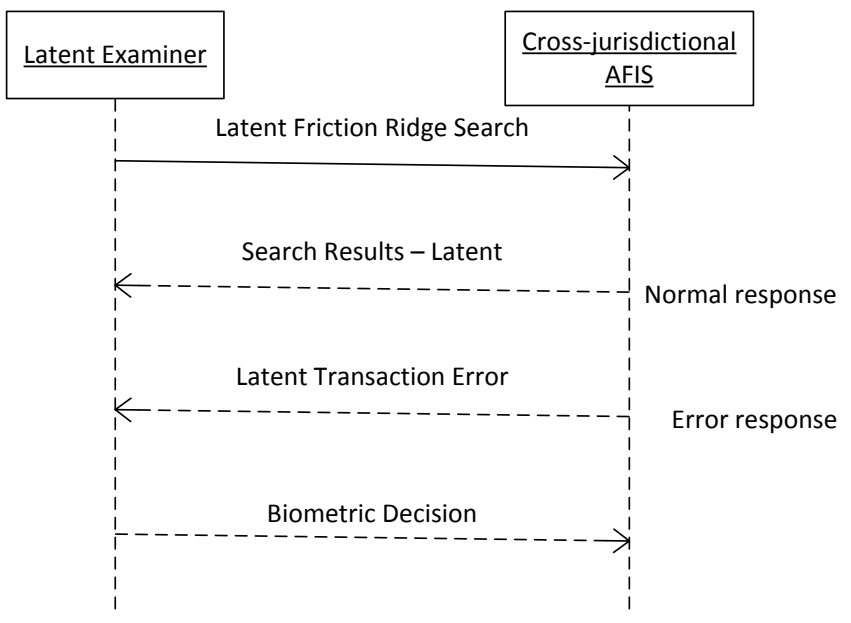

Figure 1-Latent friction ridge search and response.

The Search Results - Latent (SRL) transaction returned by the target AFIS includes a candidate list composed of names and identification numbers of each candidate. In addition, if the MOU permits and the latent examiner requested the latent image to be stored in the target AFIS's ULF, the SRL transaction shall return the identification number of the stored latent image.

The Latent Transaction Error (ERRL) transaction is returned by the target AFIS in response to a transaction that contained errors such as missing or inadequate quality fingerprints, missing mandatory information, or invalid contents. The ERRL transaction shall include additional information on the causes for the rejection. (See appendix c.)

The Biometric Decision (BDEC) transaction provides the examiner the ability to provide a definitive determination on the comparison between a latent print image and another image (i.e., identification, nonidentification, or inconclusive) to the target AFIS. The submission includes the identification number associated with the biometric for which the decision is made and the decision being made. If a positive decision by the owner of the fingerprint image is made against an image in the target AFIS's ULF, that image is removed from the ULF.

\subsubsection{Image Request and Response}

Figure 2 depicts how a latent examiner may retrieve images from the target AFIS's database(s) to assist in comparisons using the Image Request (IRQ) transaction. The latent examiner provides the identification number(s) of the subject(s) and indicators for which biometrics are being requested, such as fingerprints and palmprints. 


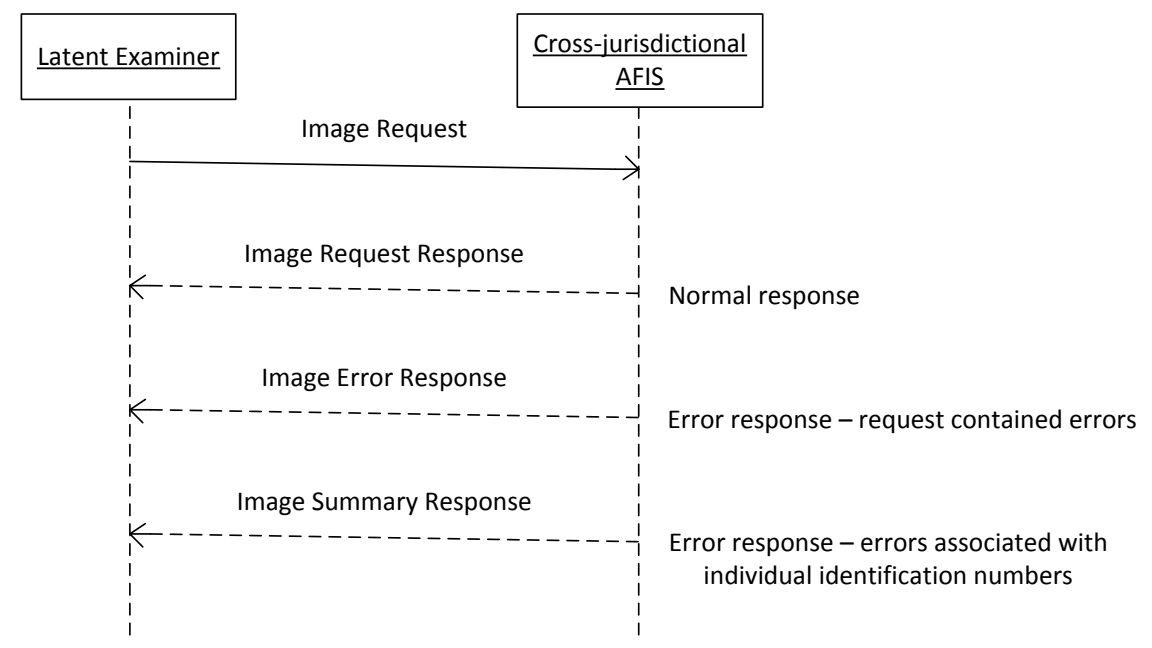

Figure 2-Image request and response.

Each identification number in the request and each set of biometrics being returned for the subject shall be addressed in a separate Image Request Response (IRR) transaction. If the request contains any errors, an Image Error Response (ERRI) transaction shall be returned, including the reason for the return. Errors associated with individual identification numbers, such as an image set not being on file, shall be reported in the Image Summary Response (ISR) transaction. (See appendix c.)

\subsection{Unsolved Latent File Transactions}

\subsubsection{Unsolved Latent Match and Biometric Decision}

The Unsolved Latent Match (ULM) transaction is an unsolicited message to the owner of the unsolved latent friction ridge image, not to the submitter of the newly submitted friction ridge search. The owner of the unsolved latent case is responsible for conducting the comparison. To the latent print examiner, the process is identical to Tenprint to Unsolved Latent (TP/UL) search results on their AFIS system. 
If a positive identification decision resulting from a Unsolved Latent Match (ULM) is made using a Biometric Decision (BDEC) transaction against a latent print in the target AFIS's ULF, that print will be removed from the ULF.

(Note: This workflow is predicated on the assumption that the MOU permits cross-jurisdictional inserts into the target AFIS ULF.)

\subsubsection{Unsolicited Unsolved Latent Delete}

An Unsolicited Unsolved Latent Delete (UULD) transaction is sent by the AFIS when a record has been deleted from the target AFIS's ULF. If a set of unsolved latent images was added from a multifinger latent search, the UULD transaction is used to indicate that that applies to the entire set of images added.

(Note: This workflow is predicated on the assumption that the MOU permits cross-jurisdictional inserts into the target AFIS ULF.)

\subsubsection{Unsolved Latent File Maintenance Transactions}

The Unsolved Latent Record Delete Request (ULD) transaction requests that records be removed from the target AFIS's ULF. If a set of unsolved latent images was added from a multifinger latent search, the ULD transaction applies to the entire set of images added. The Unsolved Latent Delete Response (ULDR) transaction is used to indicate to the latent examiner that a record has been deleted from the target AFIS's ULF in response to a ULD transaction.

(Note: This workflow is predicated on the assumption that the MOU permits cross-jurisdictional inserts into the target AFIS ULF.) 


\section{Transactions}

Transactions are subdivided into the following categories:

- Queries and Responses

- Unsolved Latent File Transactions

\subsection{Application Profile Specification}

An LITS transaction shall include a set of subfields for APS 1.016-Application Profile Specification as follows:

Table 1-APS 1.016-Application Profile Specifications

\begin{tabular}{|l|l|l|l|}
\hline Field Number & Mnemonic & Content Description & Value \\
\hline 1.016 & APO & Application Profile Organization & "NIST/OLES" \\
\hline APN & Application Profile Name & "LITS" \\
\hline APV & Application Profile Version Number & "1.0" \\
\hline
\end{tabular}

The Application Profile reference to LITS may be in addition to other Application Profile references, such as FBI CJIS EBTS. The resulting transaction shall be conformant with all listed Application Profile references.

\subsection{Implementation Domain}

When a transaction corresponds to more than one Application Profile, it is recommended that DOM 1.013-Domain Name be set to the primary Application Profile's domain name and version number. For example, a LITS transaction that also conforms to FBI CJIS EBTS should set field 1.013 as follows:

Table 2-DOM 1.013-Domain Name

\begin{tabular}{|l|l|l|l|}
\hline Field Number & Mnemonic & Content Description & Value \\
\hline \multirow{2}{*}{1.013} & DNM & Domain Name & "NORAM" \\
\cline { 2 - 4 } & DVN & Domain Version Number & "9.3" \\
\hline
\end{tabular}

\subsection{Identification Numbers}

To accommodate the variety of identification number types associated with different AFIS systems, LITS pairs UCN 2.2033A-FBI Number/UCN ${ }^{12}$ and NDR 2.098-Named Data Repository in the SRL transaction to allow the latent examiner to determine the type of identification number. As examples of such variations, UCN 2.2033A-FBI Number/UCN is 100 alphanumeric characters ${ }^{13}$ and State identification numbers are 3-10 characters that may end with a hyphen for certain States. The format and content of local identification numbers has not yet been explored fully.

\footnotetext{
${ }^{12} \mathrm{UCN}=$ Universal Control Number.

${ }^{13}$ Field length change proposed for FBI CJIS EBTS v9.4.
} 


\subsection{Queries}

Latent AFIS search queries are predicated on the following:

- Search types
- Latent Print to Tenprint (LT/TP)
- Latent Print to Latent Print (LT/LT)
- Latent Palm to Reference Palm Palmprint

- Search categories
○ Latent Fingerprint
- Latent Palmprint
- Supplementals ${ }^{14}$

\subsubsection{Record Set Requirements}

Table 3 contains the record set requirements for queries.

Table 3-Record Set Requirements for Queries

\begin{tabular}{|l|c|c|c|c|c|c|c|c|}
\hline \multicolumn{1}{|c|}{ TOT } & $\mathrm{T} 1$ & $\mathrm{~T} 2$ & $\begin{array}{c}\text { Latent Images } \\
(\mathrm{T4} 4 \mathrm{~T}, \mathrm{~T} 13)^{15}\end{array}$ & $\mathrm{T9}$ & $\mathrm{T} 10$ & $\mathrm{~T} 14$ & $\mathrm{~T} 15$ & $\mathrm{~T} 17$ \\
\hline LFIS $^{16}$ & 1 & $1-2$ & $1-10$ & - & - & - & - & - \\
\hline LFFS $^{17}$ & 1 & $1-2$ & $1-10$ & $1-10$ & - & - & - & - \\
\hline IRQ & 1 & 1 & - & - & - & - & - & - \\
\hline BDEC & 1 & 1 & - & - & - & - & - & - \\
\hline
\end{tabular}

(Note: Only one latent image record type, i.e., Type-4, Type-7, or Type-13, is permitted in a Latent Friction Ridge Search, i.e., LFIS or LFFS.)

The Basic AFIS Implementation shall implement a single friction ridge image in a single Latent Friction Ridge Search (i.e., LFIS or LFFS). The Optional AFIS Implementation may implement multiple friction ridge images in a single Latent Friction Ridge Search (i.e., LFIS or LFFS).

If the MOU permits cross-jurisdictional inserts into the target AFIS ULF, two Type- 2 records may be present in an LFFS or LFIS Type of Transaction (TOT) only in the case that the search is to be added to the unsolved latent file and that there are suppositional Type-2 fields used to reduce file penetration. The Type-2 record for insertion into the ULF includes only known data, whereas the other Type-2 record includes data specified solely to reduce the search space.

\footnotetext{
${ }^{14}$ Supplemental fingerprints include extreme tips of fingers and full finger views that include the lower segments/joints of the fingers.

${ }^{15}$ Use of Type-13 records is preferred; use of Type-4 or Type-7 records is acceptable.

${ }^{16}$ EFS Profile 0: Image-Only Profile.

${ }^{17}$ An image shall be included in an LFFS transaction except in the case of optional EFS Profiles 20-21.
} 


\subsubsection{Latent Friction Ridge Image Search (LFIS)}

The Latent Friction Ridge Image Search (LFIS) transaction corresponds to EFS Profile 0: Image-Only Profile. No ANSI/NIST-ITL Type-9 record shall be included in the transaction associated with the friction ridge image in the Type-x record (where $x=4,7$, or 13 ).

(Note: The code for EFS Profile 0 is never entered in field 9.303 because there is no corresponding Type9 record.)

Image and region of interest size requirements shall conform to EFS Profiles, Section 3 Image/region of interest size requirements.

LFIS transactions are transmitted along with the search criteria by the latent examiner. The friction ridge features are extracted automatically from the images by the target AFIS with no human intervention. There is no manual editing of friction ridge characteristics.

(Note: The search image is mandatory in this transaction.)

The NDR 2.098-Named Data Repository field shall be set to the value of the target AFIS. The target AFIS conducts a search and transmits the results to the latent examiner. If images are of insufficient quality for the target AFIS to extract features and perform a search, the target AFIS responds with an ERRL transaction.

This transaction may include an indication that the latent image should be stored in the target AFIS'S ULF if permitted by the MOU. This transaction may include an optional field to search a target AFISspecific database, such as ULF, sex offenders, or other actions as permitted by the MOU. This transaction may include an indication whether features and matched minutiae for each candidate print image shall be returned in the Search Results-Latent (SRL) transaction.

\subsubsection{Latent Friction Ridge Features Search (LFFS)}

The Latent Friction Ridge Features Search (LFFS) transaction corresponds to the following:

- EFS Profile 1: Minimal Markup Profile

- EFS Profile 2: Quick Minutiae Search Profile

- EFS Profile 3: Detailed Markup Profile

FSP 9.303-EFS feature set profile, the optional numeric field used to indicate an EFS Profile, shall be set to the EFS Profile number (i.e., 1, 2, or 3) to indicate the specific set of EFS fields that are included in the Latent Friction Ridge Features Search transaction. If a Latent Friction Ridge Features Search transaction is conformant with two or more EFS Profiles, the code for each profile shall be entered in a separate subfield of field 9.303. Use of these profiles requires inclusion of the image in the transaction. LITSconformant systems shall implement EFS Profile 2: Quick Minutiae Search Profile and may additionally implement other EFS Profiles.

Image and region of interest size requirements shall conform to EFS Profiles, Section 3 Image/region of interest size requirements. 
The latent friction ridge features are extracted by the latent examiner and transmitted along with the search criteria.

(Note: The search image is mandatory in this transaction.)

The NDR 2.098-Named Data Repository field shall be set to the value of the target AFIS. The target AFIS conducts a search and transmits the results to the latent examiner. If images are of insufficient quality for the target AFIS to extract features and perform a search, the target AFIS responds with a Latent Transaction Error (ERRL) message. (See appendix c.)

The Latent Friction Ridge Features Search (LFFS) transaction may include an indication that the latent image should be stored in the target AFIS'S ULF if permitted by the MOU. This transaction may include an optional field to search a target AFIS-specific database, such as ULF, sex offenders, or other actions as permitted by the MOU. This transaction may include an indication of whether features and matched minutiae for each candidate print image shall be returned in the Search Results-Latent (SRL) transaction.

\subsubsection{Image Request (IRQ)}

The Image Request (IRQ) transaction enables latent examiners to retrieve images from the target AFIS's database(s) so a comparison may be made by the latent examiner or to populate the latent examiner's database. The latent examiner provides the identification number(s) of the subject(s) and indicators for which biometrics are being requested, such as fingerprints, palmprints, and/or face images.

An IRQ transaction shall contain a list of identification numbers, such as FBI 2.014-FBI number (UCN), SID 2.015-State Identification Number, or MNU 2.017-Miscellaneous Identification Number. The ICD with the target AFIS shall specify which identification numbers it will accept, for example, a State AFIS may accept only SID 2.015-State Identification Number.

Each identification number in the request and each set of biometrics being returned for the subject shall be addressed in a separate Image Request Response (IRR) transaction. If the request contains any errors, an ERRI transaction will be returned, including the reason for the return. Errors associated with individual identification numbers, such as an image set not being on file, shall be reported in the Image Summary Response (ISR) transaction. (See appendix c.) The remaining valid subject identifier numbers shall result in individual ISR transactions.

\subsubsection{Biometric Decision (BDEC)}

The Biometric Decision (BDEC) transaction provides the examiner the ability to provide a definitive determination on the comparison between a latent print image and another image, such as identification, nonidentification, or inconclusive. The transaction shall include the identification number associated with the biometric for which the decision is made and the decision being made. If a positive decision by the owner of the fingerprint image is made against an image in the target AFIS's ULF, that image is removed from the ULF. 


\subsection{Responses}

\subsubsection{Record Set Requirements}

Table 4 contains the record set requirements for Responses.

Table 4-Record Set Requirements for Responses

\begin{tabular}{|l|c|c|c|c|c|c|c|c|}
\multicolumn{1}{|c|}{ TOT } & T1 & T2 & $\begin{array}{c}\text { Fingerprint Exemplars } \\
(\mathrm{T4}, \mathrm{T} 14)\end{array}$ & $\begin{array}{c}\text { Latent Prints } \\
(\mathrm{T7}, \mathrm{T} 13)\end{array}$ & T9 & T10 & $\begin{array}{c}\text { Palmprint Exemplars } \\
\text { (T15) }\end{array}$ & T17 \\
\hline SRL & 1 & 1 & $0-99$ & $0-99$ & $0-109^{18}$ & - & $0-99$ & - \\
\hline ERRL & 1 & 1 & - & - & - & - & - & - \\
\hline IRR & 1 & 1 & $0-14$ & $0-10$ & $0-14$ & $0-10$ & $0-10$ & - \\
\hline ERRI & 1 & 1 & - & - & - & - & - & - \\
\hline ISR & 1 & 1 & - & - & - & - & - & - \\
\hline
\end{tabular}

(Note: A Search Results - Latent (SRL) transaction may contain different image record types.)

\subsubsection{Search Results - Latent (SRL)}

The Search Results - Latent (SRL) transaction is returned by the target AFIS in response to a latent friction ridge search request (LFFS or LFIS). It shall include a candidate list composed of names and identification numbers of each candidate (up to the Number of Candidates Returned (NCR) field value) along with the corresponding friction ridge image(s) of the number of images specified in the NIR 2.2010-Number of Images Requested field of the search message using the Type-4, 14, or 15 records. Up to 99 candidates, their match scores, and the finger/palm/supplemental positions of the images on file that matched may be included in the response.

If the NIR 2.2010-Number of Images Requested is not specified, then the top 20 matching images shall be returned. If the NCR 2.079-Number of Candidates Returned is not specified, then the top 20 candidates shall be included in the candidate list.

The latent examiner may optionally select in an LFIS or LFFS transaction whether features and matched minutiae for each candidate print image shall be returned in the SRL response. The features and matched minutiae shall reside in the EFS section of the Type-9 record for the candidate(s). When the RFR 2.095-Request Features Record field is set, the probe features shall be Information Designation Character $(I D C)=1$, and the candidate list images/features shall be IDC $=2$.

In addition, if the MOU permits and if the search included an indication that the latent image should be stored in the target AFIS's ULF, the SRL shall return the identification number of the stored latent image.

The Search Results - Latent (SRL) transaction shall contain a candidate list of potential matches, CNL 2.2033-Candidate Investigative List, from the target AFIS. The NDR 2.098-Named Data Repository field shall be set to the value of the target AFIS. The combination of UCN 2.2033A-FBI Number/UCN and NDR 2.098-Named Data Repository allows the latent examiner to determine the type of identification number returned in the SRL transaction.

\footnotetext{
${ }^{18}$ The Search Results - Latent (SRL) transaction returns features if EFS Profiles 30 or 31 are implemented.
} 
The legacy CAN 2.064-Candidate List is supported for backwards compatibility with older AFIS that are conformant to versions of FBI CJIS EBTS prior to v9.3.

\subsubsection{Latent Transaction Error (ERRL)}

The Latent Transaction Error (ERRL) transaction is returned by the target AFIS in response to an LFFS or LFIS transaction that contains errors, such as missing or inadequate quality fingerprints, missing mandatory information, or invalid contents. The ERRL transaction shall include additional information on the causes for the rejection. (See appendix c.)

\subsubsection{Image Request Response (IRR)}

The Image Request Response (IRR) transaction returns requested images on file with the target AFIS to the latent examiner. Each identification number in the request having images available triggers a separate response. The response shall include the identification number and the requested friction ridge images. If requested, the Type-9 records shall be included as well.

The Image Request Response (IRR) transaction shall contain the same identification number type as the Image Request (IRQ) that triggered it (for example, FBI 2.014-FBI number (UCN), SID 2.015-State Identification Number, or MNU 2.017-Miscellaneous Identification Number, which are mutually exclusive). The ICD with the target AFIS shall specify which identification numbers it will return, for example, a State AFIS may return only SID 2.015-State Identification Number.

\subsubsection{Image Error Response (ERRI)}

The Image Error Response (ERRI) transaction is returned by the target AFIS to indicate a transaction error. It includes a message field indicating the type of error detected. (See appendix c.)

\subsubsection{Image Summary Response (ISR)}

The Image Summary Response (ISR) transaction is returned by the target AFIS to summarize the results of the image request processing. This transaction shall contain the listing of each identification number returned. It is suggested that the submitting agency compare the original image request and this image summary response to determine which images were not returned because of invalid identification number or an image not being on file.

\subsection{Unsolved Latent File Transactions}

\subsubsection{Record Set Requirements}

Table 5 contains the record set requirements for Unsolved Latent File Transactions.

Table 5-Record Set Requirements for Unsolved Latent File Transactions

\begin{tabular}{|l|c|c|c|c|c|c|c|c|c|c|}
\hline TOT & T1 & T2 & T4 & T7 & T9 & T10 & T13 & T14 & T15 & T17 \\
\hline ULM & 1 & 1 & $1-14$ & $0-10$ & $0-10^{19}$ & - & $0-10$ & $0-14$ & $-{ }^{20}$ & - \\
\hline UULD & 1 & 1 & - & - & - & - & - & - & - & - \\
\hline
\end{tabular}

\footnotetext{
${ }^{19}$ The Unsolved Latent Match (ULM) transaction returns features if EFS Profiles 30 or 31 are implemented.

${ }^{20}$ From FBI CJIS EBTS, "Type-15 images apply for Palmprint Enrollment and Major Case Print Collections in conjunction with tenprint submissions."
} 


\begin{tabular}{|l|c|c|c|c|c|c|c|c|c|c|}
\hline TOT & T1 & T2 & T4 & T7 & T9 & T10 & T13 & T14 & T15 & T17 \\
\hline ULD & 1 & 1 & - & - & - & - & - & - & - & - \\
\hline ULDR & 1 & 1 & - & - & - & - & - & - & - & - \\
\hline
\end{tabular}

\subsubsection{Unsolved Latent Match (ULM)}

The Unsolved Latent Match (ULM) transaction is issued when a newly submitted friction ridge search in the target AFIS matches an unsolved latent case previously submitted by a latent examiner. This transaction is an unsolicited response to the "owner" of the unsolved latent friction ridge image, not to the submitter of the newly submitted friction ridge search. This transaction shall include the identification number of the stored latent image and the images of the unsolved latent friction ridge. The Unsolved Latent Match (ULM) shall return the complete image set that was matched against the ULF. If the submission is not retained by the target AFIS, up to 14 images may be returned in this transaction when a tenprint record hits against multiple latents in the ULF. The "owner" of the unsolved latent case is responsible for conducting the comparison.

\subsubsection{Unsolicited Unsolved Latent Delete (UULD)}

The Unsolicited Unsolved Latent Delete (UULD) transaction is used to indicate that a record has been deleted from the target AFIS's ULF. If a set of unsolved latent images were added from a multifinger latent search, the UULD transaction applies to the entire set of images added.

\subsubsection{Unsolved Latent Record Delete Request (ULD)}

The Unsolved Latent Record Delete Request (ULD) transaction requests that records be removed from the target AFIS's ULF. If a set of unsolved latent images were added from a multifinger latent search, the ULD transaction applies to the entire set of images added.

\subsubsection{Unsolved Latent Delete Response (ULDR)}

The Unsolved Latent Delete Response (ULDR) transaction is used to indicate to the latent examiner that a record has been deleted from the target AFIS'S ULF in response to a ULDR transaction. 


\section{Type-2 Logical Record Requirements}

\subsection{Data Dictionary}

Table 4 contains the descriptions and field specifications for the Type-2 record being included with a LITS transaction.

\subsubsection{CSD 2.1401-Case Description}

The Case Description (CSD) field shall contain the free-text description of the case contained in the transaction, corresponding to CIN 2.010-Contributor Case Identifier Number.

\subsubsection{CSN 2.1402-Case Name}

The Case Name (CSN) field shall contain the free-text name of the case contained in the transaction, corresponding to CIN 2.010-Contributor Case Identifier Number.

\subsubsection{IMN 2.1403-Image Number}

The Image Number (IMN) field shall contain the image number within a case to differentiate between multiple latent impressions associated within a single case. This differs from CIX 2.011-Contributor Case Identifier Extension in that each search of an AFIS system requires a distinct CIX, even if multiple searches of a single latent print are conducted.

\subsubsection{IML 2.1404-Impression Letter}

The Impression Letter (IML) field shall contain the impression letter within an image to differentiate between multiple latent impressions within a single image. For example, if the image 5677 contains a simultaneous impression of four fingerprints, they would all share the same image number (e.g., IMN $2.1403=$ " 5677 "), and each fingerprint would have a distinct impression letter (e.g., IML $2.1404=$ "A"<us>"B"<us>"C"<us>"D").

\subsubsection{STR 2.1406-Source Transaction Reference}

The Source Transaction Reference (STR) field is used in a Comparison (COMP), Analysis (ASYS), or Casework Exchange (CWE) transaction to identify the transaction(s) or file(s) that were the sources of images or features. STR 2.1406-Source Transaction Reference shall contain one occurrence for each image in the transaction and one occurrence for each Type- 9 record that was imported from another ANSI/NIST-ITL transaction.

(Note: STR 2.1406-Source Transaction Reference shall not have an occurrence for a Type-9 record created in the Comparison (COMP) transaction.)

For example, if a Comparison (COMP) transaction is created using a latent image and features from an LFFS transaction and one or more exemplar images and features from an SRL transaction, this field indicates the source of each image and feature record in the resulting Comparison (COMP) transaction.

(Note: If for a given IDC, the image comes from one source and the feature set comes from another, there are two occurrences of STR, each of which points to a different source.) 
Note that field STR 2.1406-Source Transaction Reference may be used with the source representation (Type-20), which may include a specific reference to the source file (EFR 20.994-External file reference), with a hash value (HAS 20.996-Hash).

Table 6-Field Edit Specifications for Type-2 Fields

\begin{tabular}{|c|c|c|c|c|c|c|c|c|}
\hline & & & & & \multicolumn{2}{|c|}{ Field Size } & \multicolumn{2}{|c|}{ Occurrence Count } \\
\hline Identifier & $\begin{array}{l}\text { Field } \\
\text { Number }\end{array}$ & Field Name & Condition & Character & Min & Max & Min & Max \\
\hline CSD & 2.1401 & Case Description & & ANS & 1 & 300 & 0 & 1 \\
\hline CSN & 2.1402 & Case Name & & ANS & 1 & 99 & 0 & 1 \\
\hline IMN & 2.1403 & Image Number & & $\mathrm{N}$ & 1 & 99 & 0 & 99 \\
\hline \multirow[t]{2}{*}{ IML } & 2.1404 & Impression Letter & & A & 1 & 1 & 0 & 99 \\
\hline & 2.1405 & $\begin{array}{l}\text { Reserved for } \\
\text { future use }\end{array}$ & & & & & & \\
\hline STR & 2.1406 & $\begin{array}{l}\text { Source } \\
\text { Transaction } \\
\text { Reference }\end{array}$ & & & & & 1 & $\begin{array}{l}\text { \# of image } \\
\text { records } \\
+ \text { number of } \\
\text { imported T9 } \\
\text { records }\end{array}$ \\
\hline IDC & $2.1406 \mathrm{~A}$ & $\begin{array}{l}\text { Information } \\
\text { Designation } \\
\text { Character }\end{array}$ & $M$ & $\mathrm{~N}$ & 2 & 2 & 2 & 2 \\
\hline STT & $2.1406 B$ & $\begin{array}{l}\text { Source Type of } \\
\text { Transaction }\end{array}$ & $\mathrm{C}^{22}$ & A & 3 & 5 & 3 & 5 \\
\hline SID & $2.1406 C$ & $\begin{array}{l}\text { Source } \\
\text { Information } \\
\text { Designation } \\
\text { Character }\end{array}$ & $C^{22}$ & $\mathrm{~N}$ & 2 & 2 & 2 & 2 \\
\hline STN & $2.1406 \mathrm{D}$ & $\begin{array}{l}\text { Source } \\
\text { Transaction } \\
\text { Control Number }\end{array}$ & $C^{22}$ & $\mathrm{ANS}^{23}$ & 10 & 40 & 10 & 40 \\
\hline SFP & $2.1406 \mathrm{E}$ & $\begin{array}{l}\text { Source } \\
\text { Finger/Palm } \\
\text { Position }\end{array}$ & $\mathrm{C}^{22}$ & $\mathrm{~N}$ & 2 & 2 & 2 & 2 \\
\hline RNU & $2.1406 \mathrm{~F}$ & $\begin{array}{l}\text { Source Record } \\
\text { Number }\end{array}$ & $C^{22}$ & $\mathrm{NS}^{23}$ & 1 & 1 & 1 & 5 \\
\hline SFN & $2.1406 \mathrm{G}$ & Source Filename & $M^{24}$ & $\mathrm{ANS}^{23}$ & & & 2 & 128 \\
\hline COM & $2.1406 \mathrm{H}$ & Comment & $M$ & $\mathrm{ANS}^{23}$ & & & 2 & 200 \\
\hline
\end{tabular}

\footnotetext{
${ }^{21}$ NIST Law Enforcement Standards Office (OLES).

22 If the source is an ANSI/NIST-ITL transaction, then information items STT 2.1406B-Source Type of Transaction through RNU 2.1406F-Source Record Number, inclusive, are mandatory. If the source is not an ANSI/NIST-ITL transaction (e.g., an image file), then information items STT 2.1406B-Source Type of Transaction through RNU 2.1406F-Source Record Number, inclusive, are not used.

${ }^{23} \mathrm{~S}=$ any printable 7-bit ASCII character.

${ }^{24}$ SFN 2.1406G-Source Filename, COM 2.1406H-Comment, or both, are mandatory regardless of source.
} 


\begin{tabular}{|c|c|c|c|c|c|c|c|c|}
\hline Identifier & $\begin{array}{c}\text { Field } \\
\text { Number }\end{array}$ & Field Name & Condition & Character & Min & Max & Min & Max \\
\hline $\begin{array}{l}2.1407- \\
2.1499\end{array}$ & $\begin{array}{l}\text { Reserved for } \\
\text { future use }\end{array}$ & & & & & & \\
\hline
\end{tabular}

(Note: The combination of CIN 2.010-Contributor Case Identifier Number, 2.1404 IMN-Image number, and IML 2.1404-Impression Letter provides a means for an agency to unambiguously refer to any impression.

Table 7 provides detailed descriptions of the information items that comprise the STR 2.1406-Source Transaction Reference.

Table 7-STR 2.1406-Source Transaction Reference Information Items

Information Item

Information Designation Character

Source Type of Transaction

Source Information Designation Character

Source Transaction Control Number

Source Finger/Palm Position

\section{Source Record Number}

\section{Description}

IDC of the image and/or feature record within the current transaction

Type of transaction for the source of this record

IDC of this image and/or feature record in the source transaction

Transaction Control Number of the source transaction

Finger/palm position ${ }^{25}$ of this image and/or feature record in the source transaction; generally, the finger/palm position is same in source and current transaction, but current transaction may correct an error or an unspecified position in the source

The image record number $(4,7,13,14,15,19,20,21)$ and/or the feature record number (9); if image and feature record from the same file, image and feature record numbers both included, commadelimited in numeric order (e.g., "4,9" or "9,13" or "9,14"); generally, record number not changed between source transaction and the current transaction, but permissible to be changed from legacy record format (e.g., from Type-4 to Type14) or to correct errors (e.g., if palm image was in a Type-14 record in the source transaction)

${ }^{25}$ ANSI/NIST-ITL (2011), Table 8 Friction ridge position code and recommended image dimensions. 

transactions do not have distinct filenames (as for some AFIS responses or if image acquired from a scanner), Source Filename may be omitted

Comment

Optional text description of source; if filename not specified, this field shall state the source (e.g,. "IAFIS transaction" or "Image directly acquired from scanner")

Table 8 contains an example of a COMP transaction that is the result of combining an LFFS and its SRL, where the latent image (Type-13) comes from the LFFS, but the latent features (Type-9) and images/features for 20 exemplars come from the SRL. In this example, some exemplar images in the SRL were in Type-4 records, and some were in Type-14 records.

Table 8-Example of COMP Transaction Based on ANSI/NIST-ITL Transactions.

\begin{tabular}{|c|c|c|c|c|c|c|}
\hline $\begin{array}{c}\text { Field } \\
\text { Number }\end{array}$ & Identifier & $\begin{array}{l}\text { Latent } \\
\text { Image }\end{array}$ & $\begin{array}{l}\text { Latent } \\
\text { Features }\end{array}$ & Exemplar 1 & Exemplar 2 & Exemplar 20 \\
\hline $2.1406 \mathrm{~A}$ & IDC & 1 & 1 & 2 & 3 & 21 \\
\hline $2.1406 B$ & STT & LFFS & SRL & SRL & SRL & SRL \\
\hline $2.1406 C$ & SID & 1 & 21 & 1 & 2 & 20 \\
\hline 2.1406D & STN & 1234567890 & a987654321 & a987654321 & a987654321 & a987654321 \\
\hline $2.1406 \mathrm{E}$ & SFP & 0 & 0 & 2 & 3 & 3 \\
\hline $2.1406 \mathrm{~F}$ & RNU & 13 & 9 & 4,9 & 9,14 & 9,14 \\
\hline $2.1406 \mathrm{G}$ & SFN & & & & & \\
\hline $2.1406 \mathrm{H}$ & COM & $\begin{array}{l}\text { IAFIS } \\
\text { transaction }\end{array}$ & $\begin{array}{l}\text { IAFIS } \\
\text { transaction }\end{array}$ & $\begin{array}{l}\text { IAFIS } \\
\text { transaction }\end{array}$ & $\begin{array}{l}\text { IAFIS } \\
\text { transaction }\end{array}$ & $\begin{array}{l}\text { IAFIS } \\
\text { transaction }\end{array}$ \\
\hline
\end{tabular}

Table 9 contains an example of a COMP transaction that is the result of combining one or more image files (rather than an ANSI/NIST-ITL transaction) with features contained in one or more files (e.g., NIST Special Database SD-27). In this case, the STT 2.1406B-Source Type of Transaction through RNU 2.1406F-Source Record Number information items are left blank, and SFN 2.1406G-Source Filename is set to the filename (without path) so there is some means to track from where the image came.

Table 9-Example of COMP Transaction Based on Image Files.

\begin{tabular}{|c|c|c|c|c|c|}
\hline $\begin{array}{c}\text { Field } \\
\text { Number }\end{array}$ & Identifier & Latent Image & $\begin{array}{l}\text { Latent } \\
\text { Features }\end{array}$ & Exemplar Image & $\begin{array}{l}\text { Exemplar } \\
\text { Features }\end{array}$ \\
\hline $2.1406 \mathrm{~A}$ & IDC & 1 & 1 & 2 & 2 \\
\hline $2.1406 B$ & STT & & LFFS & & LFFS \\
\hline $2.1406 C$ & SID & & 1 & & 1 \\
\hline 2.1406D & STN & & TestA001GM & & TestA001mm \\
\hline $2.1406 E$ & SFP & & 0 & & 2 \\
\hline
\end{tabular}




\begin{tabular}{|l|l|l|l|l|l|}
$\begin{array}{c}\text { Field } \\
\text { Number }\end{array}$ & \multicolumn{1}{|c|}{ Identifier } & \multicolumn{1}{|c|}{ Latent Image } & \multicolumn{1}{|c|}{$\begin{array}{c}\text { Latent } \\
\text { Features }\end{array}$} & \multicolumn{1}{|c|}{$\begin{array}{c}\text { Exemplar Image } \\
\text { Features }\end{array}$} \\
\hline 2.1406F & RNU & & 9 & 9 \\
\hline 2.1406 G & SFN & A001G.BMP & A001GM.LFF & A001M_2.BMP & A001MM.LFF \\
\hline 2.1406H & COM & NIST SD-27 & NIST SD-27 & NIST SD-27 & NIST SD-27 \\
\hline
\end{tabular}

\subsection{Summary Field List}

Table 10 and Table 11 contain column headers for each transaction and row headers that specify the tag number and ID for each field. ${ }^{26}$ The cell at the intersection of any given row and column summarizes information about the use of that field (row) in that transaction (column). If the cell is blank, the field is not defined for use in that record. Otherwise, the number in the cell gives the maximum number of occurrences of that field for that record. If the cell is shaded, then the field shall be optional for that transaction. If the cell is unshaded, then the field shall be mandatory for that transaction. In all cases, the minimum number of occurrences for a mandatory field shall be one. In all cases, the minimum number of occurrences for an optional field shall be zero. Type-2 fields not documented below (e.g., those specified in the negotiated ICD that are not in LITS or FBI CJIS EBTS) may be used as appropriate.

Table 10-Summary Field List for Basic AFIS Implementation

\begin{tabular}{|c|c|c|c|c|c|c|c|c|}
\hline Type-2 Field & LFIS & LFFS & IRQ & BDEC & SRL & ERRL & IRR & ERRI \\
\hline 2.001 LEN & 1 & 1 & 1 & 1 & 1 & 1 & 1 & 1 \\
\hline 2.002 IDC & 1 & 1 & 1 & 1 & 1 & 1 & 1 & 1 \\
\hline $2.003 \mathrm{FFN}$ & & & & & & 1 & & \\
\hline 2.006 ATN & 1 & 1 & 1 & 1 & 1 & 1 & 1 & 1 \\
\hline 2.007 SCO & 9 & 9 & 9 & & 9 & 9 & 9 & 9 \\
\hline \multicolumn{9}{|l|}{2.009 OCA } \\
\hline $2.010 \mathrm{CIN}$ & 1 & 1 & & 1 & 1 & 5 & & \\
\hline $2.011 \mathrm{CIX}$ & 1 & 1 & & 1 & 1 & 5 & & \\
\hline 2.012 LCN & & & & & 1 & & & \\
\hline $2.014 \mathrm{FBI}$ & & & 1,000 & & & & 1 & 1 \\
\hline 2.015 SID & & & 1,000 & & & & 1 & 1 \\
\hline \multicolumn{9}{|l|}{$2.016 \mathrm{SOC}$} \\
\hline 2.017 MNU & & & 1,000 & & & 4 & 1 & \\
\hline 2.018 NAM & & & & & & & 1 & \\
\hline 2.020 РОВ & 1 & 1 & & & & & & \\
\hline 2.023 AGR & 1 & 1 & & & & & & \\
\hline 2.024 SEX & 1 & 1 & & & & & & \\
\hline 2.025 RAC & 1 & 1 & & & & & & \\
\hline 2.026 SMT & 10 & 10 & & & & & & \\
\hline $2.028 \mathrm{HTR}$ & 1 & 1 & & & & & & \\
\hline 2.030 WTR & 1 & 1 & & & & & & \\
\hline 2.031 EYE & 1 & 1 & & & & & & \\
\hline $2.032 \mathrm{HAl}$ & 1 & 1 & & & & & & \\
\hline
\end{tabular}

${ }^{26}$ Deviations from FBI CJIS EBTS are indicated with an asterisk. 


\begin{tabular}{|c|c|c|c|c|c|c|c|c|}
\hline Type-2 Field & LFIS & LFFS & IRQ & BDEC & SRL & ERRL & IRR & ERRI \\
\hline 2.034 PAT & 1 & 1 & & & & & & \\
\hline 2.035 PPA & & & & & & & 1 & \\
\hline 2.036 PHT & & & & & & & 1 & \\
\hline 2.044 GEO & 5 & 5 & & & & & & \\
\hline 2.057 FNR & & & 13 & & & & & \\
\hline 2.059 SRF & & & & 1 & & & & \\
\hline 2.060 MSG & & & & & & 11 & & 11 \\
\hline $2.061 \mathrm{CST}$ & & & & & & 1 & & \\
\hline 2.062 IMT & & & & & & & 1 & \\
\hline 2.064 CAN & & & & & 99 & & & \\
\hline 2.067 IMA & 1 & & & & & & & \\
\hline 2.073 CRI & 3 & 3 & 3 & 3 & 3 & 3 & 3 & 3 \\
\hline 2.074 FGP & 10 & 10 & & & 99 & & & \\
\hline 2.076 PRI & 1 & 1 & & & & & & \\
\hline 2.079 NCR & 1 & 1 & & & 1 & & & \\
\hline 2.083 ULF & 1 & 1 & & & 1 & & & \\
\hline 2.084 AMP & & & & & & & 13 & \\
\hline 2.086 SCNA & & & & & 1 & & & \\
\hline $2.089 \mathrm{MSC}$ & & & & & 99 & & & \\
\hline 2.091 RCD1 & 1 & 1 & & & & & & \\
\hline 2.092 RCD2 & 1 & 1 & & & & & & \\
\hline 2.095 RFR & 1 & 1 & 1 & & & & & \\
\hline 2.098 NDR* & 10 & 10 & & & & & & \\
\hline 2.1401 CSD & 1 & 1 & & & 1 & & & \\
\hline 2.1402 CSN & 1 & 1 & & & 1 & & & \\
\hline 2.1403 IMN & 99 & 99 & & & 99 & & & \\
\hline $2.1404 \mathrm{IML}$ & 99 & 99 & & & 99 & & & \\
\hline 2.2010 NIR & 1 & 1 & & & 1 & & & \\
\hline $2.2033 \mathrm{CNL}$ & & & & & 99 & & & \\
\hline 2.2034 ULR & & & & 1 & & & & \\
\hline
\end{tabular}

Table 11-Summary Field List for Optional AFIS Implementation

\begin{tabular}{|l|c|c|c|c|c|c|c|c|}
\hline Type-2 Field & LFFS $^{27}$ & SRL $^{28}$ & ULM & UULD & ULD & ULDR & ISR \\
\hline 2.001 LEN & 1 & 1 & 1 & 1 & 1 & 1 & 1 \\
\hline 2.002 IDC & 1 & 1 & 1 & 1 & 1 & 1 & 1 \\
\hline 2.006 ATN & 1 & 1 & 1 & 1 & 1 & 1 & 1 \\
\hline 2.007 SCO & 9 & 9 & & & 9 & & 9 \\
\hline 2.010 CIN & 1 & 1 & 1 & 1 & 1 & 1 & \\
\hline 2.011 CIX & 1 & 1 & 1 & 1 & 1 & 1 & \\
\hline 2.012 LCN & & 1 & & & & & \\
\hline
\end{tabular}

${ }^{27}$ EFS Profile 3: Detailed Markup Profile.

${ }^{28}$ EFS Profile 30: Search Response Profile with All, and Corresponding, Minutiae. 


\begin{tabular}{|c|c|c|c|c|c|c|c|}
\hline Type-2 Field & LFFS $^{27}$ & $\mathrm{SRL}^{28}$ & ULM & UULD & ULD & ULDR & ISR \\
\hline 2.014 FBI & & & 1 & 1 & & & 1,000 \\
\hline 2.015 SID & & & & & & & 1,000 \\
\hline 2.018 NAM & & & 1 & & & & \\
\hline 2.019 AKA & & & 10 & & & & \\
\hline 2.020 РОВ & 1 & & 1 & & & & \\
\hline $2.021 \mathrm{CTZ}$ & & & 1 & & & & \\
\hline $2.022 \mathrm{DOB}$ & & & 5 & & & & \\
\hline 2.023 AGR & 1 & & & & & & \\
\hline 2.024 SEX & 1 & & 1 & & & & \\
\hline 2.025 RAC & 1 & & 1 & & & & \\
\hline 2.026 SMT & 10 & & 10 & & & & \\
\hline $2.027 \mathrm{HGT}$ & & & 1 & & & & \\
\hline 2.028 HTR & 1 & & & & & & \\
\hline 2.029 WGT & & & 1 & & & & \\
\hline 2.030 WTR & 1 & & & & & & \\
\hline 2.031 EYE & 1 & & 1 & & & & \\
\hline $2.032 \mathrm{HAl}$ & 1 & & 1 & & & & \\
\hline 2.034 PAT & 1 & & & & & & \\
\hline 2.035 PPA & & & 1 & & & & \\
\hline 2.036 PHT & & & 1 & & & & \\
\hline 2.038 DPR & & & 1 & & & & \\
\hline 2.044 GEO & 5 & & & & & & \\
\hline 2.060 MSG & & & 1 & 11 & & & \\
\hline 2.062 IMT & & & 1 & & & & 1,000 \\
\hline 2.064 CAN & & 99 & & & & & \\
\hline $2.073 \mathrm{CRI}$ & 3 & 3 & 3 & 3 & 3 & 3 & 3 \\
\hline 2.074 FGP & 10 & 99 & 10 & & & & \\
\hline 2.076 PRI & 1 & & & & & & \\
\hline 2.079 NCR & 1 & 1 & & & & & \\
\hline 2.083 ULF & 1 & 1 & & & & & \\
\hline \multicolumn{8}{|l|}{2.084 AMP } \\
\hline 2.086 SCNA & & 1 & 1 & 1 & 1 & 1 & \\
\hline 2.089 MSC & & 99 & & & & & \\
\hline 2.091 RCD1 & 1 & & & & & & \\
\hline 2.092 RCD2 & 1 & & & & & & \\
\hline 2.095 RFR & 1 & & & & & & \\
\hline 2.098 NDR* & 10 & & & & & & \\
\hline 2.1401 CSD & 1 & 1 & 1 & & & & \\
\hline 2.1402 CSN & 1 & 1 & 1 & & & & \\
\hline 2.1403 IMN & 99 & 99 & 99 & & & & \\
\hline $2.1404 \mathrm{IML}$ & 99 & 99 & 99 & & & & \\
\hline 2.2010 NIR & 1 & 1 & & & & & \\
\hline 2.2033 CNL & & 99 & & & & & \\
\hline
\end{tabular}




\section{Type-9 Logical Record Requirements}

The Type-9 record of a LITS transaction shall be populated per the field requirements as defined in the EFS Profile for the EFS Profile(s) in the transaction. 


\section{Appendix A Casework Annotation and Exchange}

These transactions are intended for exchange between human examiners or for archiving information associated with the ACE-V process. These transactions are not intended for AFIS interaction.

\section{A.1 Record Set Requirements}

Table 12 contains the record set requirements for Casework Annotation and Exchange. The Comparison (COMP) and Analysis (ASYS) transactions contain records known or believed to have originated from a single piece of friction ridge skin. The Casework Exchange (CWE) transaction is a collection of images within a single case, which may or may not be from a single individual.

Table 12-Record Set Requirements for Casework Annotation and Exchange

\begin{tabular}{|c|c|c|c|c|c|c|c|c|c|c|c|c|}
\hline TOT & T1 & T2 & T9 & T10 & T13 & T14 & T15 & T17 & T18 & T19 & T20 & T21 \\
\hline COMP & 1 & 1 & $\begin{array}{c}2- \\
\mathrm{T} 13, \mathrm{~T} 14, \mathrm{~T} 15, \mathrm{~T} 19\end{array}$ & - & * & $*$ & $*$ & - & - & $*$ & - & $*$ \\
\hline ASYS & 1 & 1 & 1 & - & 1 & - & - & - & - & - & $*$ & * \\
\hline CWE & 1 & 1 & $*$ & $*$ & $*$ & $*$ & $*$ & $*$ & $*$ & $*$ & $*$ & $*$ \\
\hline
\end{tabular}

\section{A.1.1 Comparison (COMP)}

The Comparison (COMP) transaction provides for the transmission of at least two friction ridge images and the Type- 9 records containing their associated markup. The prints may be latent or exemplar and finger, palm, or plantar. This is not an arbitrary association; the friction ridge images were selected or screened by some process and declared candidates for comparison, for example, friction ridge images returned by an AFIS or suspects resulting from casework.

All of the prints in a COMP transaction purport to be from a single area of friction ridge skin (i.e., all prints are known, or are alleged, to be from a single finger of a subject, not from all of the fingers of a subject.) A COMP transaction is not solely for individualization determinations and may be used to document the rationale for an exclusion or inconclusive determination. A COMP transaction may also be used to annotate decisions comparing a print with AFIS search results, such as providing markup justification for comparison decisions made based on a latent search (e.g., LFFS) and response (e.g., SRL) transactions.

The COMP transaction defines the information content and determination of a comparison of multiple friction ridge impressions as discerned by a latent examiner during comparison and evaluation for archiving, for interchanges with other examiners, for validation and quality assurance processing, and for quantitative analysis.

Feature markup is not required for the COMP transaction, but if it is present, the appropriate EFS Profile shall be set. 
Of particular interest in a COMP transaction are the corresponding features:

- AOC 9.360-EFS area of correspondence

- CPF 9.361-EFS corresponding points or features

- ECD 9.362-EFS examiner comparison determination

These fields are used to define the areas or points that correspond or do not correspond between two or more of the images in the current transaction. When images are compared as candidates for individualization (potential mates), the corresponding areas and points may be retained in these fields; similarly, the reasons for complex exclusions may be indicated. Corresponding features may be marked using any type of feature and are explicitly not limited to minutiae.

Comparison features are especially appropriate in transactions in which one latent image is bundled with one or more candidate/potential match images to show which areas and points in the latent image correspond to areas and points in the candidate images. Such transactions may be useful for exchanges between examiners or for communicating results from AFIS searches.

\section{A.1.2 Analysis (ASYS)}

The Analysis (ASYS) transaction provides the latent examiner the means to define the information content of a single friction ridge impression as discerned during analysis for archiving, for interchanges with other examiners, for validation and quality assurance processing, and for quantitative analysis. An ASYS transaction provides a means to provide detailed markup and annotation for a single impression that is not associated with other prints. For example, it provides a means to include detailed annotation that may not be appropriate for inclusion in an LFFS transaction.

Feature markup is not required for the ASYS transaction, but if it is present, the appropriate EFS Profile shall be set.

\section{A.1.3 Casework Exchange (CWE)}

The Casework Exchange (CWE) transaction provides a format for latent examiners to collect all information related to a case within a single transaction. This transaction permits the storage and exchange of fingerprint; palmprint; plantar; facial/mugshot; scar, mark and tattoo; iris; deoxyribonucleic acid (DNA); and other biometric sample and forensic information that may be used in the identification or verification process of a subject.

This transaction may contain the source representation (Type-20) from which other biometric Record Types were derived; for example, a high-resolution color image in a Type-20 record and two latent fingerprint images are segmented, rescaled, and gray-scaled for storage in separate Type-13 records. This transaction may contain associated contextual information (Type-21), such as an image of the area where latent fingerprints were captured. Type-2 fields may be used as appropriate. 
This information may be cached for use by the latent examiner at a later date or may be exchanged with another latent examiner as part of non-AFIS casework.

\section{A.2 Summary Field List}

Table 13 contains column headers that show each transaction and row headers that specify the tag number and ID for each field. ${ }^{29}$ The cell at the intersection of any given row and column summarizes information about the use of that field (row) in that transaction (column). If the cell is blank, the field is not defined for use in that record. Otherwise, the number in the cell gives the maximum number of occurrences of that field for that record. If the cell is shaded, then the field shall be optional for that transaction. If the cell is unshaded, then the field shall be mandatory for that transaction. In all cases, the minimum number of occurrences for a mandatory field shall be one. In all cases, the minimum number of occurrences for an optional field shall be zero. Type-2 fields not documented below, such as those specified in the negotiated ICD that are not in LITS or FBI CJIS EBTS, may be used as appropriate.

Table 13-Summary Field List for Casework Annotation and Exchange

\begin{tabular}{|l|c|c|}
\hline Type-2 Field & COMP & ASYS \\
\hline 2.001 LEN & 1 & 1 \\
\hline 2.002 IDC & 1 & 1 \\
\hline 2.006 ATN & 1 & 1 \\
\hline 2.007 SCO & 9 & 9 \\
\hline 2.009 OCA & & \\
\hline 2.010 CIN & 1 & 1 \\
\hline 2.011 CIX & 1 & 1 \\
\hline 2.012 LCN & 1 & \\
\hline 2.020 POB & 1 & 1 \\
\hline 2.023 AGR & 1 & 1 \\
\hline 2.024 SEX & 1 & 1 \\
\hline 2.025 RAC & 1 & 1 \\
\hline 2.026 SMT & 10 & 10 \\
\hline 2.028 HTR & 1 & 1 \\
\hline 2.030 WTR & 1 & 1 \\
\hline 2.031 EYE & 1 & 1 \\
\hline 2.032 HAI & 1 & 1 \\
\hline 2.034 PAT & 1 & 1 \\
\hline 2.044 GEO & 5 & 5 \\
\hline 2.064 CAN & 99 & \\
\hline 2.067 IMA & 1 & 1 \\
\hline 2.073 CRI & 3 & 3 \\
\hline 2.074 FGP & 10 & 10 \\
\hline 2.076 PRI & 1 & 1 \\
\hline 2.079 NCR & 1 & 1 \\
\hline 2.083 ULF & 1 & 1 \\
\hline & & \\
\hline
\end{tabular}

${ }^{29}$ Deviations from FBI CJIS EBTS are indicated with an asterisk. 


\begin{tabular}{|l|c|c|}
\hline Type-2 Field & COMP & ASYS \\
\hline 2.089 MSC & 99 & \\
\hline 2.091 RCD1 & 1 & 1 \\
\hline 2.092 RCD2 & 1 & 1 \\
\hline 2.095 RFR & 1 & 1 \\
\hline 2.098 NDR & 10 & 10 \\
\hline 2.1401 CSD & 1 & 1 \\
\hline 2.1402 CSN & 1 & 1 \\
\hline 2.1403 IMN & 99 & 99 \\
\hline 2.1404 IML & 99 & 99 \\
\hline 2.1406 STR & 99 & \\
\hline 2.2010 NIR & 1 & 1 \\
\hline 2.2030 PPD & 10 & \\
\hline 2.2033 CNL & 99 & \\
\hline
\end{tabular}




\section{Appendix B Latent Case Processing Scenarios}

\section{B.1 Neighboring City}

A latent print examiner of a large city near the state border has a print from a homicide that has been searched on the local and State AFIS systems as well as IAFIS/NGI with no match. Given the proximity of a large city in the adjacent state, the examiner believes a search of the neighboring city is warranted. The search produces a match of an individual whose prints were legal for the neighboring city to maintain, but not to forward to the FBI CIIS. A warrant is executed.

\section{B.2 Better Impression}

A series of shootings has occurred along the interstate. Ridge impressions were found on both shell casings and cigarette packages discovered th the site of the shootings. Although the shootings occurred within the same state, they occurred in different political boundaries. The investigation is handled by the Sheriff's Department, which would like to search the AFIS databases of the two large cities located within the county since a search of the State and CJIS databases have produced no results. A search of the city AFIS produces a match. Upon closer inspection, an examiner determines that the city had an older, but more complete, friction ridge impression than the state or CJIS.

\section{B.3 International}

A city on an international border has an informal agreement with a non-U.S. city to search highly publicized latent print cases on each other's AFIS. Each agency agrees that this is a valuable tool and would be willing to elevate the process with a formal MOU, but the technical issues of crossjurisdictional searching make this impossible on a regular basis. The uniform method of searching each other's databases presented in LITS and Markup now allows those cross searches to become routine.

\section{B.4 Newer AFIS}

All cities and counties within a State share the same database through a statewide AFIS, which had its last update four years ago. Several large cities and counties maintain their own AFIS and latent print services. The latent print examiner in a large city has searched both the State database and IAFIS/NGI with no identification. The examiner searches the adjacent county and makes an identification. A later examination reveals that the individual has a record on both the State and IAFIS/NGI databases, but the newer coder and matchers on the adjacent system resulted in the identification.

\section{B.5 Military}

Authorities at a military installation have had several burglaries related to weapons. The latent prints have been searched against the Department of Defense (DoD) Automated Biometric Identification System (ABIS) and the CIS IAFIS/NGI with no result. Given the proximity to a large city, the military latent print examiners search the city AFIS. The identification of several individuals is made based on their misdemeanor records at the city, which were not forwarded to DoD ABIS or CJIS IAFIS/NGI. Warrants are issued. 


\section{B.6 Highly Publicized}

Several carjackings within a few weeks have terrorized the city. Six latent fingerprints have been recovered from the abandoned vehicles. The latent print staff is overwhelmed and requests assistance from neighboring agencies. The latent print examiners at the neighboring agencies search several AFIS systems using Markup. An identification is made, and a warrant is executed.

\section{B.7 Natural Disaster}

A tidal surge has left many unidentified victims. Ridge impressions have been taken from the victims and delivered to the latent print examiners at several agencies. These agencies have different AFIS systems and varying database size. Collectively, the examiners are able to use this network of systems to make identifications not possible on each individual system. 


\section{Appendix C Transaction Error Messages}

\begin{tabular}{|c|c|c|c|c|c|c|}
\hline Code & Error Condition & $\begin{array}{l}\text { MDD Error } \\
\text { Description }\end{array}$ & Count & Insert \#1 & Insert \#2 & $\begin{array}{l}\text { Insert } \\
\# 3\end{array}$ \\
\hline A0001 & $\begin{array}{l}\text { Unauthorized } \\
\text { ULF delete }\end{array}$ & $\begin{array}{l}\text { Requested deletion } \\
\text { from ULF is not } \\
\text { authorized. }\end{array}$ & 0 & & & \\
\hline A0004 & $\begin{array}{l}\text { Unauthorized } \\
\text { LITS Transaction }\end{array}$ & $\begin{array}{l}\text { Requestor is not } \\
\text { authorized for } \\
\text { transaction type \%1. }\end{array}$ & 1 & $\begin{array}{l}\text { TOT of } \\
\text { incoming } \\
\text { message }\end{array}$ & & \\
\hline E0001 & $\begin{array}{l}\text { Required } \\
\text { element missing }\end{array}$ & $\begin{array}{l}\text { Mandatory element } \\
\% 1 \text { was not supplied } \\
\text { in message. }\end{array}$ & 1 & $\begin{array}{l}\text { Element } \\
\text { name }\end{array}$ & & \\
\hline E0002 & $\begin{array}{l}\text { Element failed } \\
\text { validation }\end{array}$ & $\begin{array}{l}\text { Element } \% 1 \text {, with } \\
\text { value of [\%2] contains } \\
\text { invalid data. }\end{array}$ & 2 & $\begin{array}{l}\text { Element } \\
\text { name }\end{array}$ & Element value & \\
\hline E0003 & $\begin{array}{l}\text { Element failed } \\
\text { validation }\end{array}$ & $\begin{array}{l}\text { Element } \% 1, \text { with } \\
\text { value of [\%2] contains } \\
\text { invalid data. The data } \\
\text { may not comply with } \\
\text { the acceptable range } \\
\text { of values. }\end{array}$ & 2 & $\begin{array}{l}\text { Element } \\
\text { name }\end{array}$ & Element value & \\
\hline E0004 & $\begin{array}{l}\text { LITS record } \\
\text { parse error }\end{array}$ & $\begin{array}{l}\text { LITS logical record } \\
\text { type \%1 containing } \\
\text { IDC of [\%2] in } \\
\text { message does not } \\
\text { comply with message. } \\
\text { Contents or Length } \\
\text { field values or the } \\
\text { record is not parsable. }\end{array}$ & 2 & $\begin{array}{l}\text { Logical record } \\
\text { type }\end{array}$ & $\begin{array}{l}\text { IDC value or the } \\
\text { value }-1 \text { if the } \\
\text { named logical } \\
\text { record is missing } \\
\text { or is a Type- } 1 \\
\text { record. }\end{array}$ & \\
\hline E0005 & $\begin{array}{l}\text { LITS field parse } \\
\text { error }\end{array}$ & $\begin{array}{l}\text { LITS field \%1 could not } \\
\text { be parsed. Check use } \\
\text { of separator } \\
\text { characters and } \\
\text { presence of all } \\
\text { required subfields. }\end{array}$ & 1 & Field tag & & \\
\hline E0006 & $\begin{array}{l}\text { Field } \\
\text { relationship } \\
\text { error }\end{array}$ & $\begin{array}{l}\text { The value of element } \\
\% 1 \text { is inconsistent } \\
\text { with the value of } \\
\text { element } \% 2 \text {. }\end{array}$ & 2 & $\begin{array}{l}\text { Element } \\
\text { name }\end{array}$ & Element name & \\
\hline E0012 & $\begin{array}{l}\text { Message Length } \\
\text { Inconsistent }\end{array}$ & $\begin{array}{l}\text { The length of the CJIS } \\
\text { WAN message is } \\
\text { inconsistent with the } \\
\text { sum of the lengths of } \\
\text { the logical records } \\
\text { contained within it. }\end{array}$ & 0 & & & \\
\hline
\end{tabular}




\begin{tabular}{|c|c|c|c|c|c|c|}
\hline Code & Error Condition & $\begin{array}{l}\text { MDD Error } \\
\text { Description }\end{array}$ & Count & Insert \#1 & Insert \#2 & $\begin{array}{l}\text { Insert } \\
\# 3\end{array}$ \\
\hline LOOO2 & $\begin{array}{l}\text { Subject does } \\
\text { not exist in } \\
\text { Criminal or Civil } \\
\text { File }\end{array}$ & $\begin{array}{l}\text { Subject with identifier } \\
\% 1 \text { does not exist in } \\
\text { repository. }\end{array}$ & 1 & UCN & & \\
\hline L0004 & $\begin{array}{l}\text { File image not } \\
\text { available }\end{array}$ & $\begin{array}{l}\text { The images for subject } \\
\text { identifier } \% 1 \text { are not } \\
\text { available from } \\
\text { repository } \% 2 \text {. }\end{array}$ & 2 & UCN & NDR & \\
\hline L0005 & $\begin{array}{l}\text { High } \\
\text { Penetration } \\
\text { Search Rejected }\end{array}$ & $\begin{array}{l}\text { Latent search } \\
\text { penetration estimate } \\
\text { of } \% 1 \text { percent exceeds } \\
\text { the allowable limit of } \\
\% 2 \text { percent. }\end{array}$ & 2 & $\begin{array}{l}\text { Request } \\
\text { percent }\end{array}$ & $\begin{array}{l}\text { Authorization } \\
\text { cap }\end{array}$ & \\
\hline L0006 & $\begin{array}{l}\text { Invalid image } \\
\text { type }\end{array}$ & $\begin{array}{l}\text { The supplied image(s) } \\
\text { could not be used for } \\
\text { characterization of } \\
\text { subject. }\end{array}$ & 0 & & & \\
\hline L0007 & $\begin{array}{l}\text { Features not } \\
\text { usable }\end{array}$ & $\begin{array}{l}\text { The supplied features } \\
\text { could not be used for } \\
\text { requested search. }\end{array}$ & 0 & & & \\
\hline $\mathrm{LOOOB}^{30}$ & $\begin{array}{l}\text { Characteristics } \\
\text { quality low }\end{array}$ & $\begin{array}{l}\text { The quality of the } \\
\text { characteristics is too } \\
\text { low to be used. }\end{array}$ & 0 & & & \\
\hline LOOO9 & $\begin{array}{l}\text { Image } \\
\text { decompression } \\
\text { error }\end{array}$ & $\begin{array}{l}\text { An error occurred } \\
\text { during decompression } \\
\text { of the fingerprint } \\
\text { images. }\end{array}$ & 0 & & & \\
\hline L0012 & ULF Delete Error & $\begin{array}{l}\text { An error was } \\
\text { encountered in } \\
\text { processing the } \\
\text { requested deletion } \\
\text { from the Unsolved } \\
\text { Latent File. }\end{array}$ & 0 & & & \\
\hline L0013 & $\begin{array}{l}\text { General Logic } \\
\text { Error }\end{array}$ & $\begin{array}{l}\text { A general logic error } \\
\text { was detected that is } \\
\text { not currently defined. } \\
\text { Optional error } \\
\text { message: } \% 1 \% 2 \% 3 \text {. }\end{array}$ & $0-3$ & Free text & Free text & \\
\hline L0014 & $\begin{array}{l}\text { ULF Delete } \\
\text { Subject Missing }\end{array}$ & $\begin{array}{l}\text { Cannot perform the } \\
\text { ULF delete request for } \\
\% 1 \text { because the } \\
\text { subject is not present }\end{array}$ & 1 & SCNA & & \\
\hline
\end{tabular}

${ }^{30}$ When a candidate was associated with the submission, this error message includes a formatted response reflecting "Candidate(s) were found. Please resubmit a new set of fingerprints for comparison to the candidate(s)." 


\begin{tabular}{|c|c|c|c|c|c|c|}
\hline Code & Error Condition & $\begin{array}{l}\text { MDD Error } \\
\text { Description }\end{array}$ & Count & Insert \#1 & Insert \#2 & $\begin{array}{l}\text { Insert } \\
\# 3\end{array}$ \\
\hline & & in the ULF. & & & & \\
\hline L0018 & $\begin{array}{l}\text { Latent search } \\
\text { queue full }\end{array}$ & $\begin{array}{l}\text { The requested search } \\
\text { exceeds the allocation } \\
\text { for the organization or } \\
\text { State. }\end{array}$ & 0 & & & \\
\hline L0033 & $\begin{array}{l}\text { Element Entry } \\
\text { Limit Exceeded }\end{array}$ & $\begin{array}{l}\text { The requested update } \\
\text { of this record would } \\
\text { cause the maximum } \\
\text { number of entries of } \\
\text { the } \% 1 \text { field to be } \\
\text { exceeded. }\end{array}$ & 1 & Field name & & \\
\hline L0057 & $\begin{array}{l}\text { Improper Finger } \\
\text { Specified }\end{array}$ & $\begin{array}{l}\text { Latent searches } \\
\text { cannot process } \% 1 \\
\text { possible finger } \\
\text { positions for } \% 2 \\
\text { supplied search } \\
\text { fingers. }\end{array}$ & 2 & FGN_CNT & AFV_CNT & \\
\hline L0058 & $\begin{array}{l}\text { UCN and NDR } \\
\text { format } \\
\text { incompatible }\end{array}$ & $\begin{array}{l}\text { The designated } \\
\text { repository [\%1] does } \\
\text { not correlate to the } \\
\text { provided record } \\
\text { format number (\%2). }\end{array}$ & 2 & NDR & UCN & \\
\hline L0109 & $\begin{array}{l}\text { Poor Image } \\
\text { Quality }\end{array}$ & $\begin{array}{l}\text { The quality of the } \\
\text { fingerprint images is } \\
\text { too poor to permit } \\
\text { processing. }\end{array}$ & 0 & & & \\
\hline L0115 & Other QC Error & $\begin{array}{l}\text { A Quality Check error } \\
\text { has occurred. }\end{array}$ & 0 & & & \\
\hline$L_{0116^{31}}$ & $\begin{array}{l}\text { Fingerprint } \\
\text { Pattern Quality } \\
\text { Error }\end{array}$ & $\begin{array}{l}\text { Fingerprint pattern(s) } \\
\text { not discernible }\end{array}$ & 0 & & & \\
\hline$L_{0117^{31}}$ & $\begin{array}{l}\text { Fingerprint } \\
\text { Pattern Area } \\
\text { Error }\end{array}$ & $\begin{array}{l}\text { Insufficient pattern } \\
\text { area(s) recorded for } \\
\text { identification } \\
\text { purposes }\end{array}$ & 0 & & & \\
\hline L0124 & $\begin{array}{l}\text { Unacceptable } \\
\text { Criteria }\end{array}$ & $\begin{array}{l}\text { The submission does } \\
\text { not meet latent } \\
\text { acceptance criteria. }\end{array}$ & & & & \\
\hline L0125 & Invalid ORI ${ }^{32}$ & $\begin{array}{l}\text { This ORI, \%1, is not } \\
\text { present in the CCA } \\
\text { file. }\end{array}$ & 1 & $\begin{array}{l}\text { ORI value } \\
\text { from } \\
\text { maintenance }\end{array}$ & & \\
\hline
\end{tabular}

${ }^{31}$ When a candidate was associated with the submission, this error message includes a formatted response reflecting "Candidate(s) were found. Please resubmit a new set of fingerprints for comparison to the candidate(s)." ${ }^{32} \mathrm{ORI}=$ Originating Agency ID 


\begin{tabular}{|c|c|c|c|c|c|c|}
\hline Code & Error Condition & $\begin{array}{l}\text { MDD Error } \\
\text { Description }\end{array}$ & Count & Insert \#1 & Insert \#2 & $\begin{array}{l}\text { Insert } \\
\# 3\end{array}$ \\
\hline & & & & request & & \\
\hline L0126 & Invalid CRI ${ }^{33}$ & $\begin{array}{l}\text { This CRI, \%1, is not } \\
\text { present in the CCA } \\
\text { file. }\end{array}$ & 1 & $\begin{array}{l}\text { CRI value } \\
\text { from } \\
\text { maintenance } \\
\text { request }\end{array}$ & & \\
\hline L0131 & $\begin{array}{l}\text { Required } \\
\text { element missing }\end{array}$ & $\begin{array}{l}\text { Mandatory element } \\
\% 1 \text { was omitted from } \\
\text { message. }\end{array}$ & 1 & $\begin{array}{l}\text { Element } \\
\text { name }\end{array}$ & & \\
\hline L0144 & $\begin{array}{l}\text { Field } \\
\text { Relationship } \\
\text { Error }\end{array}$ & $\begin{array}{l}\text { The value of element } \\
\% 1 \text { is inconsistent } \\
\text { with the value of } \\
\text { element } \% 2 \text {. }\end{array}$ & 2 & $\begin{array}{l}\text { Element } \\
\text { name }\end{array}$ & Element name & \\
\hline L0147 & $\begin{array}{l}\text { Contributor has } \\
\text { remote } \\
\text { capability }\end{array}$ & $\begin{array}{l}\text { The contributing state } \\
\text { has remote capability. }\end{array}$ & 0 & & & \\
\hline L0148 & $\begin{array}{l}\text { Poor Latent } \\
\text { Image Quality }\end{array}$ & $\begin{array}{l}\text { The image quality is } \\
\text { not adequate for } \\
\text { conducting an AFIS } \\
\text { search. }\end{array}$ & 0 & & & \\
\hline L0149 & $\begin{array}{l}\text { Bad Search } \\
\text { Criteria }\end{array}$ & $\begin{array}{l}\text { The descriptive search } \\
\text { criteria are not } \\
\text { adequate or are } \\
\text { incomplete. }\end{array}$ & 0 & & & \\
\hline L0151 & $\begin{array}{l}\text { Photo Not } \\
\text { Available }\end{array}$ & Photo not available. & 0 & & & \\
\hline
\end{tabular}

${ }^{33} \mathrm{CRI}=$ Controlling Agency ID 


\section{Appendix D Abbreviations}

ABIS-Automated Biometric Identification System

AFIS-Automated Fingerprint Identification System

ANSI-American National Standards Institute

ASYS-Analysis Transaction

ACE-V-Analysis, Comparison, Evaluation and Verification

BDEC-Biometric Decision

CAN-Candidate List

CIN - Contributor Case Identifier Number

CIX-Contributor Case Identifier Extension

CJIS-Criminal Justice Information Services

COMP-Comparison Transaction

$\mathrm{CNL}-$ Candidate Investigative List

CSD-Case Description

CSN-Case Name

CWE-Casework Exchange Transaction

EBTS-Electronic Biometric Transmission Specification

EFS-Extended Friction Ridge Feature Set

ERRI-Image Error Response

ERRL-Latent Transaction Error

$\mathrm{FBI}$-Federal Bureau of Investigation

IAFIS-Integrated Automated Fingerprint Identification System

ICD_Interface Control Document

IDC_Information Designation Character

IML-Impression Letter

IMN - Image Number

IRQ-Image Request

IRR-Image Request Response

ISR-Image Summary Response

LFIS - Latent Friction Ridge Image(s) Search

LFFS - Latent Friction Ridge Features Search

LITS-Latent Interoperability Transmission Specification

LT/TP - Latent Print to Tenprint

MNU - Miscellaneous Identification Number

MOU-Memorandum of Understanding

NCR-Number of Candidates Returned

NDR - Name of Designated Repository

$\mathrm{NGI}$-Next Generation Identification

NIR-Number of Images Requested

NIST-National Institute of Standards and Technology

SID-State Identification Number 
SLA-Service Level Agreement

SRL-Search Results-Latent

STR - Source Transaction Reference

TOT-Type of Transaction

UCN-Universal Control Number

ULD-Unsolved Latent Record Delete Request

ULDR-Unsolved Latent Delete Response

ULF-Unsolved Latent File

ULM-Unsolved Latent Match

UULD-Unsolicited Unsolved Latent Delete 